\title{
The DANish STOCK AND BOND MARKETS: COMOVEMENT, RETURN PREDICTABILITY AND VARIANCE DECOMPOSITION*
}

\author{
Tom Engsted* Carsten TanggaARD ${ }^{\dagger}$ \\ March 1999, This Revision May 2000
}

\begin{abstract}
VAR models of the kind developed by Shiller and Beltratti (1992) and Campbell and Ammer (1993) are used to analyze the Danish stock and bond markets and their comovement. In contrast to these papers, however, VAR parameter estimates are bias-adjusted and VAR generated statistics, including their standard errors and confidence intervals, are computed using bootstrap simulation. In addition, we modify the Campbell-Ammer variance decomposition such that it can handle returns from a long-term coupon bond. Some parts of the results for the Danish stock and bond markets are quite similar to the US results reported by Shiller and Beltratti and Campbell and Ammer, but other parts stand in sharp contrast to the results for the US. The most important differences between the US and Denmark are that in Denmark news about higher future inflation lead to an increase in expected future stock returns, and that excess stock return news and excess bond return news are negatively correlated.
\end{abstract}

JEL Codes: C32, G12.

Keywords: VAR model, present value relations, return variance decomposition, bias-correction, bootstrapping.

*We would like to thank Geert Bekaert (the editor), two anonymous referees, and Jonathan Rubin, for useful comments and Allan Wurtz for discussions of details in the paper. The usual disclaimer applies. The research is supported by a grant from the Danish Social Science Research Council.

†Both authors are at the Department of Finance, The Aarhus School of Business, Fuglesangs Alle 4, DK 8210 Aarhus V, Denmark. E-mail for Tom Engsted is tom@asb.dk. E-mail for Carsten Tanggaard is cat@asb.dk. 


\section{Introduction}

It is widely documented that expected returns in financial markets vary over time, and that - especially long-horizon - returns contain a significant predictable component. The dividend-price ratio, in particular, has proven to be a good predictor of future stock returns, and the spread between long and short interest rates has shown clear predictive power for future bond returns (see Campbell et al. (1997), chapters 2, 7, and 10 for an up-to-date account on these findings).

Most studies have treated the stock and bond markets in isolation. However, an interesting question is to what extent stock and bond prices/returns move together over time, and whether expected returns on stocks and bonds respond to the same underlying information. Barsky (1989) analyzes in a theoretical setting, based on a standard consumption-based asset pricing model, the effects of changes in risk and real economic productivity growth on the joint behaviour of stock and bond prices. He concludes that these prices may or may not move together, depending on the degree of risk-aversion of agents.

In an empirical setting Shiller and Beltratti (1992) use vector autoregressions (VAR's) to examine whether the positive correlation between stock and bond returns observed in long-term annual US and UK data (which is equivalent to a negative correlation between changes in stock prices and changes in long-term bond yields), can be explained in terms of simple rational expectations present value models, i.e. the expectations hypothesis for the term structure of interest rates and the dividend-ratio model for stock prices. They find that such simple models cannot explain the observed correlations. Campbell and Ammer (1993) undertake an analysis similar in spirit to the analysis in Shiller and Beltratti, but without imposing particular economic models on the data. Instead they develop, within a VAR framework, a variance decomposition for stock and bond returns which enables them to decompose excess returns into news about future dividends, inflation, real interest rates, and excess returns. On post war US data they find that news about future excess stock returns account for most of the variation in excess stock returns, with news about future dividends and real interest rates being less important. On the other hand, the variance of excess bond returns is not mainly the result of news about future bond returns, but is instead mostly due to news about future inflation. These results help explain the quite low positive correlation of stock and bond returns observed in post war 
US data. ${ }^{1,2}$

In this paper we analyze the joint behaviour of Danish stock and bond markets over the period 1922-1996. We apply the same basic VAR methodologies as those developed by Shiller and Beltratti (1992) and Campbell and Ammer (1993). However, we modify their methodologies in several ways. First, following Bekaert et al. (1997), we use bootstrap simulation to correct for the small-sample bias inherent in VAR parameter estimates, and we also compute standard errors and confidence intervals for the various statistics involved using bootstrap simulation. Second, instead of measuring comovement of stock and bond markets by comparing changes in stock prices and changes in bond yields, as in Shillar and Beltratti, we compare the movement in the dividend-price ratio with the movement in the long-short yield spread. Finally, we modify the Campbell-Ammer methodology such that it can handle returns from a long coupon bond. Their methodology is designed for zero-coupon bonds with a finite maturity, and cannot be used when bond returns are computed from the yields of long-term coupon bonds, which will often be the case since in many countries (including Denmark) zero-coupon yields on long bonds do not exist many years back.

The main results from the empirical analysis can be summarized as follows. First, one-year excess stock and bond returns are positively correlated, but simple present value models cannot explain this positive correlation. Second, over the whole sample period 1922-1996 and the smaller period 19221982 , most of the variation in excess stock returns is due to news about future dividends. However, for the post war period 1947-1996, news about future excess stock returns are the dominating force behind stock return movements. This points to a structural break around the beginning of the 1980s. On the other hand, a quite robust finding is that news about future long-term inflation is the primary cause behind movements in excess bond returns. Third, increases in long-term expected inflation is either no news or bad news for the stock market in the short run but good news for the stock market in the long run. By contrast, news about higher future inflation is bad news for the bond market in both the short and long run. As a consequence, news about future stock returns and news about future bond returns are negatively

\footnotetext{
${ }^{1}$ The correlation of innovations in monthly US excess stock and bond returns over the period 1952-1987 is 0.198 according to Campbell and Ammer. This is somewhat lower than the correlation of 0.366 reported by Shiller and Beltratti for annual excess stock and bond returns over the period 1948-1989.

${ }^{2}$ Patelis (1997) uses the Campbell-Ammer methodology to document that monetary policy variables are important predictors of stock returns, and that monetary policy shocks effect primarily expected returns with less effect on expected dividend growth and real interest rates.
} 
correlated. Some parts of these results are quite similar to the US results reported by Shiller and Beltratti (1992) and Campbell and Ammer (1993), but other parts stand in sharp contrast to the US results.

The rest of the paper is organized as follows. In section 2 we present the basic stock and bond market relationships that will form the basis for the subsequent VAR analyses. Section 3 describes the VAR methodology, including the bootstrap simulation procedure, and reports the empirical results based on the present value models and variance decompositions. Finally, section 4 contains some concluding remarks.

\section{The basic stock and bond relationships}

The fundamental equation characterizing the stock market is the following formula for the log dividend-price ratio, which can be derived from a firstorder Taylor approximation of the identity relating the one-period log stock return to log stock prices and log dividends, see Campbell and Shiller (1988):

$$
\delta_{t}=E_{t} \sum_{j=1}^{\infty} \rho_{s}^{j-1}\left(r_{t+j}+e_{t+j}-\Delta d_{t+j}\right)+k_{s}
$$

$\delta_{t} \equiv \log (D / P)_{t} \equiv d_{t}-p_{t} . D_{t}$ and $P_{t}$ are real dividends paid during period $t$ and real stock prices at the end of period $t$, respectively. $r_{t+j}$ is the oneperiod $\log$ real interest rate from period $t+j-1$ to $t+j$, and $e_{t+j}$ is the $\log$ excess stock return from period $t+j-1$ to $t+j$, i.e. the $\log$ stock return in excess of a short-term interest rate. $\rho_{s}$ is equal to $(1+\exp (\bar{\delta}))^{-1}$, where $\bar{\delta}$ is the mean $\log$ dividend-price ratio over the sample. $E_{t}$ and $\Delta$ are the conditional expectations operator and the first-difference operator, respectively, and $k_{s}$ is a constant arising from the linearization. From (1) Campbell (1991) derives the following basic expression for the unexpected $\log$ excess stock return from period $t$ to $t+1$

$e_{t+1}-E_{t} e_{t+1}=\left(E_{t+1}-E_{t}\right)\left\{\sum_{j=0}^{\infty} \rho_{s}^{j} \Delta d_{t+1+j}-\sum_{j=0}^{\infty} \rho_{s}^{j} r_{t+1+j}-\sum_{j=1}^{\infty} \rho_{s}^{j} e_{t+1+j}\right\}$

(2) is a dynamic accounting identity stating that positive unexpected excess stock returns are associated either with higher expected future long-term dividend growth, and/or lower expected future long-term real stock returns, 
where the latter can be decomposed into real interest rates and excess stock returns. Thus, unexpected excess stock returns are the result of either news about future dividends, news about future real interest rates, or news about future excess stock returns (or a combination of the three).

Expressions similar to (1) and (2) can be derived for the bond market. In Appendix 1 we derive the following equation relating the spread between the long-term bond yield and the short-term interest rate, $S_{t}$, to expected future changes in short-term interest rates and to expected future excess bond returns:

$$
S_{t} \equiv\left(1-\rho_{b}\right) y_{t}-i_{t}=E_{t} \sum_{j=1}^{\infty} \rho_{b}^{j} \Delta i_{t+j}+\left(1-\rho_{b}\right) E_{t} \sum_{j=0}^{\infty} \rho_{b}^{j} x_{t+j+1}+k_{b}
$$

$y_{t}$ is the log yield on a consol and $i_{t}$ is the continuously compounded oneperiod interest rate. Apart from a constant $S_{t}$ is approximately equal to the spread between the long consol yield and the short-term interest rate. $x_{t}$ is the one-period log excess bond return. In Appendix 1 we also derive an expression relating the unexpected excess bond return to news about future long-term inflation, $\pi_{t+j}$, real interest rates, $r_{t+j}$, and excess bond returns, $x_{t+j}$ :

$$
x_{t+1}-E_{t} x_{t+1}=\left(E_{t+1}-E_{t}\right) \sum_{j=1}^{\infty} \rho_{b}^{j}\left(-\pi_{t+1+j}-r_{t+1+j}-x_{t+1+j}\right)
$$

This expression shows that positive unexpected excess bond returns are due to either lower expected future long-term inflation and/or lower expected future long-term real bond returns, where the latter can be decomposed into real interest rates and excess bond returns. Campbell and Ammer (1993) derive an expression similar to (4) for the unexpected excess return on an $n$-period zero-coupon bond. This has the implication that the summation in the formula goes to $n$ - 1 instead of $\infty$, and that no discounting is involved. We will focus on (4) because in our empirical analysis we calculate returns from a long-term coupon bond instead of a zero-coupon bond.

There is no economic theory underlying equations (1), (2), (3) and (4). They are derived from the basic formulas defining stock and bond returns. Turning (1) into a theory requires imposing assumptions about how expected stock returns vary over time. For example, if expected stock returns are constant (i.e. investors are risk-neutral), $E_{t}\left(r_{t+j}+e_{t+j}\right)$ is just a constant and, hence, variation in the dividend-price ratio reflects only variation in 
expected future dividend growth. Less restrictively, we may assume that the expected stock return is equal to the short term interest rate (plus a constant) which may vary over time. In this case equation (1) becomes

$$
\delta_{t}=E_{t} \sum_{j=1}^{\infty} \rho_{s}^{j-1}\left(i_{t+j}-\Delta d_{t+j}\right)+\text { constant }
$$

Comparing (1) and (5) we also see that in (5) the price deflator used to convert nominal variables into real variables in (1), cancels out such that $\delta_{t}$ is log nominal dividends minus log nominal stock prices, and $\left(i_{t+j}-\Delta d_{t+j}\right)$ is the difference between the nominal interest rate and the growth rate in nominal dividends.

For the bond market a natural economic theory to consider is the Expectations Theory of the term structure of interest rates. This is obtained from (3) by assuming that expected excess bond returns are constant, such that

$$
S_{t}=E_{t} \sum_{j=1}^{\infty} \rho_{b}^{j} \Delta i_{t+j}+\text { constant }
$$

According to (6) the spread reflects only market expectations of future shortterm nominal interest rate changes (apart from a constant). These changes can be further decomposed into changes in real rates and changes in inflation. If, in addition, the Fisher hypothesis holds, expected changes in real rates are zero, such that the spread reflects only market expectations of future changes in inflation (see e.g. Mishkin, 1990). In (4) this corresponds to the last two terms on the right-hand side being zero, such that news about future long-term inflation is the only source of variation in bond return innovations: higher expected long-term inflation leads to an immediate increase in bond yields, which corresponds to a drop in bond prices, i.e. negative bond return innovations.

In the next section the present value models (5) and (6) will be tested and used to analyze the degree of comovement of returns in the Danish stock and bond markets. Subsequently, we use the dynamic accounting identities (2) and (4) to decompose stock and bond returns into news about future dividends, future inflation, future real interest rates, and future stock and bond returns. 


\section{The econometric methodology, and empir- ical results}

Our analysis will be based on various VAR models. Bekaert et al. (1997) document the potential small-sample biases in VAR parameter estimates, and they suggest a Monte Carlo procedure to correct for the bias. We follow their approach but in addition we invoke Kilian's (1998) procedure for avoiding unit or explosive roots. We also use bootstrap simulation to compute standard errors and confidence intervals for the various VAR based statistics. Section 3.1 describes the bootstrap procedure in more detail. Section 3.2 describes the data that we use in the empirical analyses, and sections 3.3 and 3.4 set up the particular VAR models that we use and report the empirical results.

\subsection{The bootstrap procedure}

In the empirical analysis we apply bootstrap techniques for two purposes: bias-adjustment and estimation of standard errors and confidence intervals.

It is well known that OLS estimates of parameters in VAR systems are biased in small samples. Bekaert et al. (1997) argue that this problem is especially pronounced when some of the variables are highly persistent. In our study the dividend-price ratio, in particular, is highly positively autocorrelated with a root near unity. Second, the VAR generated statistics that we compute are highly non-linear functions of the underlying VAR parameters. This implies that delta approximations of the asymptotic distributions may be very misrepresentative of the small sample distributions. Therefore, we apply a bootstrap-after-bootstrap technique (Kilian, 1998) to estimate small sample standard errors. These standard errors are useful for summarizing the precision of estimates when the distribution is 'well-behaved'. However, the estimated statistics may have severely skewed small sample distributions. In that case bootstrap interval estimates summarize better the distribution and we report those as well.

The bootstrap procedure is as follows. Consider the first-order VAR model for the vector $z_{t}$

$$
z_{t+1}=A z_{t}+\omega_{t+1} \quad, \quad t=1, \ldots, T .
$$

where $A$ is the VAR parameter matrix, and where the disturbance vector $\omega_{t+1}$ is assumed to be iid. In addition, the assumptions behind the autoregressive bootstrap are assumed to hold (Bose, 1988). Stack the free $A$ parameters in 
the vector $\theta$. The OLS estimator of $\theta$ is denoted $\widehat{\theta}$. Denote by $\widehat{\theta}^{*}$ an estimate of $\theta$ based on a bootstrap sample of size $T$ (see Bose (1988) for details). Furthermore, denote by $\bar{\theta}=\mathrm{E}^{*}\left(\widehat{\theta}^{*}\right)$ the expectation under the distribution for $\theta^{*}$ (conditional on $\widehat{\theta}$.). This expectation can be calculated with arbitrary precision by taking the average of $\widehat{\theta}^{*}$ across $B$ bootstrap samples (of size $T$ each). Then $\bar{\theta}-\widehat{\theta}$ is an estimate of the bias term, $\widehat{\theta}-\theta$ (Bekaert et al. 1997). Accordingly, $2 \widehat{\theta}-\bar{\theta}$ is a bias-adjusted estimate of $\theta$.

An important problem here is that this bias-adjusted estimate may fall into the non-stationary region of the parameter space. We follow Kilian (1998) and correct the bias-adjusted estimates. For simplicity (and illustrative purposes) assume that the original OLS estimate of $\theta$ is within the stationary region, but $\bar{\theta}$ is outside the stationary region. ${ }^{3}$ Then, for some $\rho \in[0,0.01,0.02, \ldots, 0.99], \widehat{\theta}+\rho(\widehat{\theta}-\bar{\theta})$ is within the stationary region of the parameter space. We use the largest such value of $\rho$ to construct the final bias-adjusted estimate, which we denote $\widetilde{\theta}{ }^{4}$ As Kilian emphasizes, this adjustment has no effect asymptotically and does not reduce the parameter space of the OLS estimator. However, it will affect the small sample properties. $^{5}$

In order to obtain bootstrap standard errors and confidence intervals for the various VAR generated statistics that we compute, denote by $\lambda=f(\theta)$ the statistic of interest (e.g. a correlation-coefficient or a variance ratio, see sections 3.3 and 3.4). Then the small sample distribution of $\widetilde{\lambda}=f(\widetilde{\theta})$ is easily obtained by bootstrapping, i.e. by constructing resampled values, $\tilde{\lambda}^{*}=f\left(\widetilde{\theta}^{*}\right)$, conditional on $\widetilde{\theta}^{6}$ We follow Killian and correct $\widetilde{\theta}^{*}$ for small sample bias using the same bias estimate, $\bar{\theta}-\widehat{\theta}$, as we obtained from the original data. ${ }^{7}$ We also apply the adjustment for non-stationarity procedure here with one additional feature: we discard values of $\widetilde{\theta}^{*}$ that are in the nonstationary region from the outset, i.e. before applying any bias-adjustment procedure. Finally, standard errors are obtained from the distribution of $\widetilde{\lambda}^{*}$

\footnotetext{
${ }^{3}$ If the original estimate, $\widehat{\theta}$, falls outside the stationary region no bias-adjustment is done. This does not, however, occur in any of our analyses.

${ }^{4}$ The stepsize of 0.01 for $\rho$ is suggested by Kilian.

${ }^{5}$ We did some experiments with this procedure. It had only a minor effect on most systems. However, it had a clear effect on some of the VAR systems in section 3.4 where persistence is most pronounced.

${ }^{6}$ Note, however, that there is another source of bias due to the non-linearity of $\lambda$. Correcting this bias is not straightforward, c.f. Kilian (1998), p.219.

${ }^{7}$ One could calculate a new bias-estimator for each outcome, $\tilde{\theta}^{*}$, as described above. However, this would be computationally cumbersome given the large number of simulation runs (100.000) that we conduct. In addition, as Kilian notes, this extra layer of bootstrap simulations cannot be justified asymptotically.
} 
and $95 \%$ confidence intervals are taken from the 2.5 and 97.5 percentiles of this distribution.

\subsection{The data}

The stock market data to be used in this paper are the annual Danish data from Lund and Engsted (1996) on the extended sample period 1922-1996. The stock index is a value weighted portfolio of individual stocks chosen to obtain maximum coverage of the 'market' index of the Copenhagen Stock Exchange. In constructing the data corrections were made for stock splits and new equity issues below market prices. $P_{t}$ is the stock price at the end of year $t$, while $D_{t}$ denotes dividends paid during year $t$ (the appendix in Lund and Engsted (1996) contains a more detailed description of the data). For the bond market we use the yield-to-maturity on a long coupon bond, from which we calculate approximate log one-year returns as in formula (A1) in Appendix 1 (which is based on a consol). For the period 1922-1972 the source for this series is Kærgård (1991). For the period after 1972, the source is the Yearbooks from the Danish Central Bank. As a measure of the short-term interest rate we use the Danish Central Bank's discount rate up to 1975 (from Kærgård, 1991), spliced together with a 1-month discount yield for the period thereafter (for the period 1976-1991 taken from the appendix in Engsted and Tanggaard (1994), and for the two years 1995-1996 we use the officiel 1-month 'Copenhagen InterBank Offered Rate'). ${ }^{8}$ In obtaining the real interest rate to be used in section 3.4, we compute inflation from the consumption deflator in Kærgård (1991), and updated with various publications from the Danish Statistical Bureau. (A copy of the whole dataset is available from the authors upon request).

The standard deviations of excess stock and bond returns, $e_{t}$ and $x_{t}$, i.e. the one-year log stock and bond returns in excess of the continuously compounded short-term interest rate, are $17.2 \%$ and $10.8 \%$, respectively. The correlation between $e_{t}$ and $x_{t}$ is 0.48 . Thus, stock returns are more variable than bond returns, and the stock and bond markets move together over time. ${ }^{9}$ The purpose of the analysis in the next section is to see whether simple present value models can explain this comovement.

\footnotetext{
${ }^{8}$ In Denmark a reasonable liquid market for short-term claims only existed from the middle of the 1970s. Up til then the discount rate seems to be the best proxy for the short-term interest rate.

${ }^{9}$ The average real one-year stock and bond returns are $6.2 \%$ and $4.1 \%$, respectively. In the present paper our primary interest is not in the mean values of stock and bond returns, but in their covariability. Thus, in the VAR models to be estimated below all variables are measured in deviations from their unconditional means. The average Danish equity risk-premium, i.e. the difference between the real stock return and the real short-
} 
We report results based on both the whole sample period 1922-1996, and the two sub-periods 1922-1982 and 1947-1996. This is potentially important since over the whole 74-year period one might expect that some of the major structural changes that naturally occur over such a long time period will influence the relationship between stock and bond markets. In particular, the gradual opening of the Danish stock and bond markets to foreign investors that have occurred since the beginning of the 1980s might have significantly altered this relationship. ${ }^{10}$

\subsection{Comovement based on the present value models}

Following Shiller and Beltratti (1992), the stock and bond market relationships (5) and (6) can be analyzed jointly by setting up a vector-autoregressive (VAR) model containing the variables involved, i.e. $\delta_{t},\left(i_{t}-\Delta d_{t}\right), S_{t}$, and $\Delta i_{t}$, and then examine the implications that (5) and (6) have for this VAR model. Shiller and Beltratti specify separate equations for real interest rates and the growth rate in real dividends because this is necessary in order to recover the change in stock prices from the system. They want to analyze the comovement of the change in stock prices and the change in bond yields. We choose to work with the composite variable $\left(i_{t}-\Delta d_{t}\right)$ because then we are able to ignore inflation since the variable measures the difference between nominal interest rate and the growth in nominal dividends. Then, instead of comparing the change in stocks prices with the change in bond yields, we compare the dividend-price ratio and the yield spread.

Denote by $z_{t}$ the vector

$$
z_{t}=\left[\delta_{t},\left(i_{t}-\Delta d_{t}\right), S_{t}, \Delta i_{t}\right]^{\prime}
$$

Then the first-order VAR model for $z_{t}$ is

$$
z_{t+1}=A z_{t}+\omega_{t+1}
$$

where $A$ is the VAR coefficient matrix, $\omega_{t+1}$ is the vector of error terms, and all variables are in deviations from their means. The extension to higher

term interest rate, is $3.7 \%$ which is much lower than the US equity premium. Thus, in Denmark there does not seem to be an equity premium puzzle. In Engsted et al. (2000) we investigate this in more detail.

${ }^{10}$ In 1996 foreign investors owned $15 \%$ of the Danish stock market and $18 \%$ of the Danish bond market. 
order VAR models is easily done using the companion form. An appealing feature of including $\delta_{t}$ and $S_{t}$ in the VAR system is that if (5) and (6) are true, these two variables summarize all the information that agents have about future values of $(i-\Delta d)$ and $\Delta i$. Thus, under the hypothesis that (5) and (6) holds, we do not run into problems associated with agents having information not captured by the variables of the VAR (see Campbell and Shiller, 1987).

Define selection vectors $e 1, e 2, e 3$, and $e 4$, that pick out the first, second, third, and fourth elements of $z_{t}$, respectively. Then VAR forecasts of the right-hand sides of equations (5) and (6) are:

$$
\begin{gathered}
\delta_{t}^{\prime}=e 2^{\prime} A\left(I-\rho_{s} A\right)^{-1} z_{t} \\
S_{t}^{\prime}=\rho_{b} e 4^{\prime} A\left(I-\rho_{b} A\right)^{-1} z_{t}
\end{gathered}
$$

These are the 'theoretical' values of the dividend-price ratio and the yield spread, i.e. the values that $\delta_{t}$ and $S_{t}$ should take if the stock and bond markets behave according to (5) and (6). Thus, according to (5) and (6), $\delta_{t}=\delta_{t}^{\prime}$ and $S_{t}=S_{t}^{\prime}$, which imply the following non-linear cross-equation restrictions on the VAR parameters: $e 1^{\prime}=e 2^{\prime} A\left(I-\rho_{s} A\right)^{-1}$ and $e 3^{\prime}=\rho_{b} e 4^{\prime} A\left(I-\rho_{b} A\right)^{-1}$. The economic interpretation of these restrictions is that multi-period excess returns are unpredictable based on information available at time $t$. Postmultiplying these expressions by $\left(I-\rho_{s} A\right)$ and $\left(I-\rho_{b} A\right)$, respectively, results in the following linear cross-equation restrictions: $e 1^{\prime}\left(I-\rho_{s} A\right)=e 2^{\prime} A$ and $e 3^{\prime}\left(I-\rho_{b} A\right)=\rho_{b} e 4^{\prime} A$. These linear restrictions state that one-period excess returns are unpredictable. Since the expressions for the linear restrictions are algebraically equivalent to the expressions for the non-linear restrictions, it follows that multi-period excess returns are unpredictable if and only if one-period excess returns are unpredictable. The cross-equation restrictions can be tested using likelihood ratio- or Wald statistics which have asymptotic $\chi^{2}$ distributions with degrees of freedom equal to the number of restrictions. Bekaert and Hodrick (2000) show that, in a VAR setting similar to ours, the Wald test has very poor size properties (it is heavily over-sized), so we will use the likelihood ratio test.

In addition to formally testing the cross-equation restrictions, the theoretical dividend-price ratio and yield spread can be computed using (8) and (9) and with the unrestricted VAR parameter estimates inserted in the matrix $A$. The difference between $\delta_{t}$ and $\delta_{t}^{\prime}$, and between $S_{t}^{\prime}$ and $S_{t}$, then measure the magnitude of deviations from the present value models (5) and (6). Campbell 
and Shiller (1987) argue that e.g. $\delta_{t}$ and $\delta_{t}^{\prime}$ may move closely together over time even if the cross-equation restrictions are statistically rejected, meaning that model (5) has substantial empirical content despite the formal statistical rejection. Similarly, $\delta_{t}$ and $\delta_{t}^{\prime}$ may not show a high degree of comovement even if the restrictions are not rejected, meaning that there are substantial economically important deviations from the model despite the formal nonrejection. Engsted (1998) and Engsted and Haldrup (1999) show that the variance of the difference between actual and theoretical values, where the latter are computed from the unrestricted VAR estimates, constitute an estimate of the lower bound on the variance of Durlauf and Hall's (1989) 'model noise' component, i.e. the unobserved stochastic deviations from the present value models. Thus, computing the noise ratio's $N R_{\delta}=\operatorname{var}\left(\delta-\delta^{\prime}\right) / \operatorname{var}(\delta)$ and $N R_{S}=\operatorname{var}\left(S-S^{\prime}\right) / \operatorname{var}(S)$ gives information about the fraction of the movements in $\delta_{t}$ or $S_{t}$ that are due to noise.

The actual and theoretical interrelationships between the stock and bond markets can be analyzed by examining the degree of comovement of $\delta_{t}^{\prime}$ and $S_{t}^{\prime}$, and compare it with the degree of comovement of $\delta_{t}$ and $S_{t}$. Similarly, the degree of comovement of theoretical excess stock and bond returns can be compared with the degree of comovement of actual excess stock and bond returns. Excess one-period stock returns from $t$ to $t+1$ are given as $e_{t+1} \equiv \delta_{t}-$ $\rho_{s} \delta_{t+1}-\left(i_{t+1}-\Delta d_{t+1}\right)$, and excess one-period bond returns from $t$ to $t+1$ are $x_{t+1} \equiv\left(1-\rho_{b}\right)^{-1}\left(S_{t}-\rho_{b} S_{t+1}-\Delta i_{t+1}\right)$. Thus, theoretical excess stock and bond returns can be computed from the VAR parameter estimates using (8) and (9) as $e_{t+1}^{\prime} \equiv \delta_{t}^{\prime}-\rho_{s} \delta_{t+1}^{\prime}-\left(i_{t+1}-\Delta d_{t+1}\right)$ and $x_{t+1}^{\prime} \equiv\left(1-\rho_{b}\right)^{-1}\left(S_{t}^{\prime}-\rho_{b} S_{t+1}^{\prime}-\Delta i_{t+1}\right)$.

In generating $\delta_{t}^{\prime}$ and $S_{t}^{\prime}$ from (8) and (9) (and from these $e_{t}^{\prime}$ and $x_{t}^{\prime}$ ), we use the bias-corrected VAR parameter estimates as explained in section 3.1.

\subsubsection{Empirical results}

Tables 1 to 3 contain summary statistics from VAR models estimated over the whole period 1922-1996 and the sub-periods 1922-1982 and 1947-1996, and with either one or two lags (Appendix 3 reports all the VAR parameter estimates). ${ }^{11}$ The Schwarz criterion picks a lag-length of one for sample periods 1922-1996 and 1922-1982, and two for the sample period 1947-1996. However, since the results are somewhat sensitive to the number of lags

\footnotetext{
${ }^{11}$ Appendix 3 only reports the bias-adjusted estimates. In general, the bias-adjustment does not lead to large changes in the estimates. For example, in the VAR(1) model for 1922-1996, the unadjusted and adjusted $\delta_{t}$ coefficients in the $\delta_{t+1}$ equation are 0.898 and 0.919 , respectively.
} 
chosen, we report results for both one-lag and two-lag VAR's. ${ }^{12,13}$

For the whole period and with a one-lag VAR, the results are quite favorable to the simple present value model for both stocks and bonds. The cross-equation restrictions are not rejected by the LR test at even the $20 \%$ level, and the theoretical dividend-price ratio and yield spread both show a high degree of comovement with their actual counterparts (the correlations are above 0.9 ). The noise ratio's $N R_{\delta}$ and $N R_{S}$ are $14.1 \%$ and $18.8 \%$, respectively, implying that most of the variability in $\delta_{t}$ and $S_{t}$ is due to expected future changes in $\left(i_{t}-\Delta d_{t}\right)$ and $\Delta i_{t}$, respectively. Actual and theoretical excess returns are also highly positively correlated, but here the noise ratio's are somewhat higher (26-31\%). The models are also able to generate the positive correlation between excess stock and bond returns that we observe in reality, although theoretical bond returns are almost just as variable as theoretical stock returns where in reality stock returns are much more variable than bond returns. Similarly, the models correctly predict a positive correlation between the dividend-price ratio and the yield spread, but the predicted variance ratio of $\delta$ to $S$ is much lower than it should be.

These results change when we increase the lag-length. For the $\operatorname{VAR}(2)$ model the cross-equation restrictions are strongly rejected, all noise ratio's increase, and now a (counterfactual) slightly negative correlation between excess stock and bond returns is predicted.

As noted in section 3.2, the increased openness of the Danish financial markets that have occurred since the beginning of the 1980s, may have induced a structural shift in the stock and bond market relationships. When we focus on the sub-period 1922-1982, where the Danish markets were essentially closed to foreign investors, the likelihood ratio test does not reject the present value models at a $10 \%$ level in neither the one-lag nor two-lag VAR models, and the noise ratio's $N R_{\delta}$ and $N R_{S}$ are quite low. However, the noise ratio's $N R_{e}$ and $N R_{x}$ are somewhat higher in the $\operatorname{VAR}(2)$ model (33-39\%), and the present value models cannot generate a positive correlation between the dividend-price ratio and yield spread, and between excess stock and bond returns. Thus, despite the formal non-rejection of the expectations hypoth-

\footnotetext{
${ }^{12}$ We check the stationarity of the variables involved using Augmented Dickey-Fuller tests. Except for $\delta_{t}$, which appears to be borderline non-stationary, all variables are clearly stationary. We also compute the eigenvalues of the VAR parameter matrices. None of the largest eigenvalues for the bias-adjusted systems exceed 0.96, which implies that the VAR systems are stationary. As expected, the largest eigenvalues are slightly higher for the bias-corrected systems than for the non-adjusted systems. Details are available upon request.

${ }^{13}$ The values imposed for $\rho_{s}$ and $\rho_{b}$ are: $\rho_{s}=0.962, \rho_{b}=0.921(1922-1996) ; \rho_{s}=0.956$, $\rho_{b}=0.925$ (1922-1982); $\rho_{s}=0.964, \rho_{b}=0.906$ (1947-1996). These are based on sample means of the log dividend-price ratio and the log bond yield, respectively.
} 
esis of the term structure and the dividend-ratio model for stock prices, the two models are not able to explain the observed comovement of stock and bond markets. This illustrates the usefullness of computing the theoretical values $\delta_{t}^{\prime}, S_{t}^{\prime}, e_{t}^{\prime}$, and $x_{t}^{\prime}$ and comparing them to their actual counterparts, in addition to formally testing the models.

The results for the post war period 1947-1996 strongly reject the present value models, both by the formal statistical test and by the noise ratio's. The results based on all three sample periods taken together clearly suggest that a change took place in the stock and bond market relationships somewhere around the beginning of the 1980s.

The results in this section are very similar to the results reported by Shiller and Beltratti (1992) for the US and the UK. They also find that the comovement of stock and bond markets cannot be explained in terms of simple rational expectations present value models. In the next section we go beyond these simple models and ask more generally what can be said about the various components of stock and bond returns and their interrelationships.

However, before moving to the variance decompositions, we briefly comment on the standard errors and confidence intervals reported in Tables 1 to 3. First, we notice that some of the statistics are estimated with extreme imprecision in the sub-period 1947-1996. This seems to be due to the fact that the VAR systems for this period are close to being non-stationary: the largest eigenvalues exceed 0.9 in both the one-lag and two-lag VAR models. Second, by comparing the bootstrap estimated standard errors and confidence intervals, it is obvious that several of the statistics have very non-standard and non-symmetric distributions. This emphasizes the point made in section 3.1 that one should be careful in summarizing the precision of the estimates by their standard errors.

\subsection{Variance decomposition of returns}

The purpose of the analysis in section 3.3 was to examine whether the comovement of stock and bond markets can be explained in terms of simple present value models. In this section we abstract totally from economic theory and use the dynamic accounting identities (2) and (4) to decompose excess stock and bond returns into news about its various components: dividends, real interest rates, inflation, and excess returns.

As in section 3.3 we use a VAR model to generate forecasts of the righthand sides of (2) and (4). This is similar to Campbell and Ammer (1993). However, our VAR model differs somewhat from Campbell and Ammer's. They include the one-period excess stock return as one variable of the VAR, 
but they do not include the one-period excess bond return. Instead they include the spread between a 10-year and a 1-month zero-coupon bond yield, and the first-difference of the 1-month zero-coupon yield, and then they compute the unexpected excess bond return from the residuals of these two equations of the VAR. Further, they compute the revisions of expectations of future inflation from the residuals of the real interest rate equation and the nominal interest rate change equation. In our empirical application the longterm bond is not a pure discount bond but a coupon bond from which we calculate approximate returns based on the consol formula (A1) in Appendix 1. In Appendix 2 we show that this implies that it is not possible to compute the news component of inflation in the way Campbell and Ammer do it. Instead we include the excess bond return directly as a state variable of the VAR along with the excess stock return, and then obtain the inflation news component as a residual. This requires that we also include the real interest rate as a state variable. In addition, we include the log dividend-price ratio and the first-difference of the nominal short-term interest rate because these two variables turn out to be good predictors for excess stock and bond returns and for real interest rates (see below). ${ }^{14}$

Thus, the VAR can be written as equation (7) in section 3.3 , but with $z_{t}$ defined as the vector

$$
z_{t}=\left[e_{t}, x_{t}, r_{t}, \delta_{t}, \Delta i_{t}\right]^{\prime}
$$

where $e_{t} \equiv \log \left(P_{t}+D_{t}\right)-\log \left(P_{t-1}\right)-i_{t-1}$, and $x_{t} \equiv y_{t-1}-\rho_{b} y_{t}-i_{t-1}$. In order to simplify the notation we write equations (2) and (4) as

$$
\begin{gathered}
\widetilde{e}_{t+1}=\widetilde{e}_{d, t+1}-\widetilde{e}_{r, t+1}-\widetilde{e}_{e, t+1} \\
\widetilde{x}_{t+1}=-\widetilde{x}_{\pi, t+1}-\widetilde{x}_{r, t+1}-\widetilde{x}_{x, t+1}
\end{gathered}
$$

Since excess stock and bond returns are the first two elements of $z_{t}$, the stock and bond excess return innovations, $\widetilde{e}_{t+1} \equiv e_{t+1}-E_{t} e_{t+1}$ and $\widetilde{x}_{t+1} \equiv x_{t+1}-$

\footnotetext{
${ }^{14}$ In contrast to the analysis in section 3.3, where there is no 'superior information problem' given that the present value models are true, we now face the problem that in forecasting the future, agents may use information not captured by the VAR variables. This implies that the VAR analysis gives a variance decomposition conditional on whatever information is included in the system. This is the price we have to pay for not imposing any economic theory on the econometric analysis.
} 
$E_{t} x_{t+1}$, are directly obtainable from the VAR error vector as $\widetilde{e}_{t+1}=e 1^{\prime} \omega_{t+1}$ and $\widetilde{x}_{t+1}=e 2^{\prime} \omega_{t+1}$, where the selection vectors $e 1$ and $e 2$ are defined in the same way as in section 3.3. To obtain estimates of the right-hand sides of equations (10) and (11), i.e. the long-term expectations revisions, we use the fact that $\left(E_{t+1}-E_{t}\right) z_{t+1+j}=A^{j} \omega_{t+1}$. It follows that each of the right-hand side components of (10) and (11) can be calculated as:

$$
\begin{gathered}
\widetilde{e}_{e, t+1}=\rho_{s} e 1^{\prime} A\left(I-\rho_{s} A\right)^{-1} \omega_{t+1} \\
\widetilde{e}_{r, t+1}=e 3^{\prime}\left(I-\rho_{s} A\right)^{-1} \omega_{t+1} \\
\widetilde{e}_{d, t+1}=\widetilde{e}_{t+1}+\widetilde{e}_{e, t+1}+\widetilde{e}_{r, t+1} \\
\widetilde{x}_{x, t+1}=\rho_{b} e 2^{\prime} A\left(I-\rho_{b} A\right)^{-1} \omega_{t+1} \\
\widetilde{x}_{r, t+1}=\rho_{b} e 3^{\prime} A\left(I-\rho_{b} A\right)^{-1} \omega_{t+1} \\
\widetilde{x}_{\pi, t+1}=-\widetilde{x}_{t+1}-\widetilde{x}_{r, t+1}-\widetilde{x}_{x, t+1}
\end{gathered}
$$

Note that, as in Campbell and Ammer (1993), the news about dividends component, $\widetilde{e}_{d, t+1}$, is obtained as a residual from the other three components in (14). Similarly, the news about inflation component, $\widetilde{x}_{\pi, t+1}$, is obtained as a residual in (17). The way we compute the various components of (11) differs somewhat from Campbell and Ammer (1993). In Appendix 2 we explain in more detail these differences.

Having estimated the stock and bond return innovations and their various components in the way described above, we next want to measure the relative magnitude of each of the components, and to measure how they move together over time. We calculate the relative magnitude of the news components in two ways. First, we simply compute the variances and covariances of each of the components on the right-hand sides of (10) and (11), and divide them by the variance of $\widetilde{e}_{t+1}$ (the components in (10)) and by the variance 
of $\widetilde{x}_{t+1}$ (the components in (11)). ${ }^{15}$ Secondly, we orthogonalize each of the components using a Cholesky decomposition, and then measure the $R^{2}$ values in regressions of $\widetilde{e}_{t+1}$ and $\widetilde{x}_{t+1}$ on each of the orthogonalized components. The sum of the $R^{2}$ values will then add up to one so that each individual $R^{2}$ number can be interpreted as the fraction of the innovation variance explained by that particular news component. ${ }^{16,17}$ To measure the degree of comovement of the various news components we simply report their pairwise correlation coefficients. Finally, as in section 3.3, we bias-correct the VAR parameter estimates and calculate standard errors and confidence intervals using bootstrap simulation.

\subsubsection{Empirical results}

In order to construct the variance decomposition of returns described above, the VAR model must contain at least excess stock returns, $e_{t}$, excess bond returns, $x_{t}$, and the real interest rate, $r_{t}$. However, we have also experimented with other forecasting variables and have found that including the dividendprice ratio, $\delta_{t}$, and the change in the nominal interest rate, $\Delta i_{t}$, substantially increases the predictability of these first three variables. We do not include the yield spread because this variable has no predictive power for the other variables. As in section 3.3.1 we estimate VAR models with both one and two lags, and we report results for the whole period 1922-1996 and the sub-periods 1922-1982 and 1947-1996 (the Schwarz criterion picks one lag for all three sample periods). Since the two-lag models contain quite many parameters relative to the number of observations, for these models we delete strongly insignificant parameters. In Appendix 3 we report all parameter estimates and their standard errors. Tables 4 to 9 contain summary statistics from the estimated VAR's. ${ }^{18}$

\footnotetext{
${ }^{15}$ From (10) and (11) it follows that $\operatorname{Var}(\widetilde{e})=\operatorname{Var}\left(\widetilde{e}_{d}\right)+\operatorname{Var}\left(\widetilde{e}_{r}\right)+\operatorname{Var}\left(\widetilde{e}_{e}\right)-2 \operatorname{Cov}\left(\widetilde{e}_{d}, \widetilde{e}_{r}\right)-$ $2 \operatorname{Cov}\left(\widetilde{e}_{d}, \widetilde{e}_{e}\right)+2 \operatorname{Cov}\left(\widetilde{e}_{r}, \widetilde{e}_{e}\right)$, and that $\operatorname{Var}(\widetilde{x})=\operatorname{Var}\left(\widetilde{x}_{\pi}\right)+\operatorname{Var}\left(\widetilde{x}_{r}\right)+\operatorname{Var}\left(\widetilde{x}_{x}\right)+2 \operatorname{Cov}\left(\widetilde{x}_{\pi}, \widetilde{x}_{r}\right)+$ $2 \operatorname{Cov}\left(\widetilde{x}_{\pi}, \widetilde{x}_{x}\right)+2 \operatorname{Cov}\left(\widetilde{x}_{r}, \widetilde{x}_{x}\right)$.

${ }^{16}$ Campbell and Ammer (1993, p.10) seem to claim that the $R^{2}$ values from Cholesky decomposed news components do not add up to one. This is not correct. In their Tables III and IV it is not clear (to us at least) whether the reported $R^{2}$ values are based on orthogonalized or unorthogonalized news components.

${ }^{17}$ It is well-known that the outcome of the Cholesky decomposition is not independent of the ordering of the variables. Following Patelis (1997), in the present context it is most natural to order excess returns last. In the decomposition for stock returns dividends are ordered first, followed by real interest rates. In the decomposition for bond returns, inflation is ordered first, followed by real interest rates. Fortunately, the results do not change qualitatively by reversing the ordering of dividends/inflation and real interest rates.

${ }^{18}$ None of the largest eigenvalues of the bias-adjusted VAR systems exceed 0.95 , which implies that the systems are stationary.
} 
If we first consider the whole sample period, we see that in the one-lag VAR none of the included variables significantly predict excess stock returns (the $R^{2}$ value is only $6 \%$ ), while lagged excess stock returns and the lagged dividend-price ratio have strong predictive power for excess bond returns $\left(R^{2}=27 \%\right)$. Equally interesting, the real interest rate is highly predictable from its own lag and lags of all the other four variables in the VAR. The variance decomposition shows that most of the variance of stock returns is due to the variance of news about future dividends and to the covariances of news about future dividends, real interest rates and excess returns. Based on the orthogonalized components (the $R^{2}\left(\widetilde{e}_{i}\right)$ and $R^{2}\left(\widetilde{x}_{j}\right)$ values), news about future dividends account for $79 \%$ of the variability of excess stock returns, with news about future real interest rates and excess returns being relatively unimportant. Since the variance decompositions are estimated much more precisely when they are based on the orthogonalized components (c.f. the standard errors and confidence intervals reported in Tables 4 to 9), in the following we will only comment on these. Table 7 shows that regarding excess bond returns, news about future inflation is the most important component (48\%), but here news about future real interest rates are also important (35\%). Most of these results do not change qualitatively by increasing the lag-length of the VAR. Note, however, that in the $\operatorname{VAR}(2)$ model excess stock returns are highly predictable $\left(R^{2}=20 \%\right)$, and news about future excess returns account for a non-negligible part of the variability of excess stock returns $(31 \%)$.

For the sub-period 1922-1982 news about future dividends remain the most important factor in explaining the variability of stock returns, and news about future inflation remain the most important factor in explaining bond returns (see Tables 5 and 8). News about future real interest rates and excess returns are relatively less important though not negligible. For the post war period 1947-1996 the results for stock returns are extremely sensitive to the lag-length of the VAR. In the one-lag model excess stock returns are unpredictable, and dividend news account for almost all the variation (93\%), see Table 6 . In the two-lag model, however, returns are strongly predictable, and news about future excess returns account for $83 \%$ of the variation in excess stock returns. This big difference does not show up in the variance decomposition for bond returns. Here news about future inflation remain the most important component in both the $\operatorname{VAR}(1)$ and $\operatorname{VAR}(2)$ models.

The results for stock returns based on the $\operatorname{VAR}(2)$ models, and for all three sample periods taken together, indicate that in Denmark dividends have played a much smaller role in generating return variability in recent years compared to the earlier period. Interestingly, Campbell and Ammer (1993) also find that for the US news about future dividends are much more 
important in the early period 1952-1972 compared to the later period 19731987, see their Table III. Regarding the Danish bond market, a quite robust finding across all sample periods is that news about future long-term inflation seem to be the dominating force behind movements in excess bond returns. This is consistent with the results in Engsted (1995) for Denmark showing that the long-term interest rate is a powerful predictor of future long-term inflation. ${ }^{19}$

In Tables 10 to 12 we report correlations among all the components in (10) and (11). ${ }^{20}$ First, we see that the signs of the correlations are in general quite robust to changes in sample period and lag-length of the VAR. Second, in accordance with the US results reported by Campbell and Ammer, increases in expected future long-term inflation are bad news for the Danish bond market since $\widetilde{x}_{\pi}$ is negatively correlated with both $\widetilde{x}$ and $\widetilde{x}_{x}$ : news about higher future inflation lead to both an immediate drop in bond returns and to a decrease in expected future bond returns. However, in contrast to what characterizes the US, news about higher future inflation lead to, on the one hand, an immediate drop in stock returns (except for the sub-period 19221982 where $\widetilde{x}_{\pi}$ and $\widetilde{e}$ are almost uncorrelated), but, on the other hand, an increase in expected future stock returns.

In accordance with these results, excess stock return news and excess bond return news are negatively correlated (which stands in sharp contrast to the US results reported by Campbell and Ammer), despite the fact that stock and bond returns have a positive correlation. This implies that when people discover that long-term excess stock returns will be higher than they expected, then they also tend to discover that long-term excess bond returns will be lower than expected. This may seem counter-intuitive but is due to the fact that stock and bond returns do not respond to the same variables or respond differently to the underlying variables. As seen from the VAR parameter estimates in Appendix 3, the underlying mechanisms at work here are that excess stock returns are negatively related to lagged excess bond returns, excess bond returns are negatively related to lagged excess stock returns, and lagged dividend-price ratio and interest rates have

\footnotetext{
${ }^{19}$ The finding that inflation news are the dominating force behind bond return movements could in principle be an artifact resulting from the inflation component being treated as a residual in the VAR analysis. However, we do not believe this constitutes a problem in our case because excess bond returns are strongly predictable in the estimated VAR models.

${ }^{20}$ In these tables we do not report confidence intervals because in several cases the point estimate does not lie within the interval. Kilian (1998, p.220) notes that this often happens in standard bootstrap interval estimation. The problem seems to be caused by the bias that arises due to the non-linearity of the statistics, c.f. footnote 6 .
} 
opposite effects on excess stock and bond returns. Combined with the positive correlation between actual stock and bond returns the conclusion must be that whereas the stock and bond markets move in the same direction in response to current shocks, these shocks propagate into changing expectations about returns, interest rates, dividend-price ratios, etc., which imply opposite effects on expected future stock and bond returns. However, since most of the variation in excess returns is unexpected, these latter propagation effects are not strong enough to eliminate the basic positive correlation characterizing stock and bond returns. In the US the positive correlation between excess stock return news and excess bond return news is due to the fact that similar variables forecast both stock and bond returns in the same way, c.f. Campbell and Ammer (1993, p.25).

Finally, we see that the news component of real interest rates relevant for stocks, $\widetilde{e}_{r}$, and for bonds, $\widetilde{x}_{r}$, are extremely highly correlated, which is not surprising since the only difference in the VAR based forecasts of real interest rates is the discount factors used ( $\rho_{s}$ for stocks and $\rho_{b}$ for bonds, which differ only slightly from each other).

\section{Concluding remarks}

In this paper we have analyzed the comovement of Danish stock and bond markets using long-term annual data covering the period 1922-1996. Based on various VAR models where, in accordance with the suggestions in Bekaert et al. (1997) and Kilian (1998), VAR parameter estimates have been adjusted for small-sample bias and standard errors and confidence intervals are generated using bootstrap simulation, our main findings are:

First, simple rational expectations present value models cannot explain the positive correlation between stock and bond returns that we observe in the data. Second, inflation news account for most of the variation in bond returns. Third, dividend news account for most of the variation in stock returns, although there is some indication of a structural change such that in recent years news about future stock returns account for the bulk of stock market volatility. Fourth, inflation news affect expectations of future stock and bond returns differently in the long run. Finally, stock return news and bond return news are negatively correlated, despite the fact that actual stock and bond returns are positively correlated.

Some of these results are quite similar to what Shiller and Beltratti (1992) and Campbell and Ammer (1993) have documented for the US and the UK. There are also some of the results, however, that are quite different from the results reported in those papers. An interesting topic for future research is a 
more detailed analysis of the differences between Danish and other countries asset markets. Recently, researchers have shown a large interest in documenting cross-country similarities and differences in world stock markets, see e.g. Jorion and Goetzmann (1999) and Campbell (1999). The present study, together with the analyses in Engsted et al. (2000), has added further pieces to this strand of literature.

\section{References}

Barsky, R.B. (1989): Why don't the prices of stocks and bonds move together? American Economic Review 79, 1132-1145.

Bekaert, G. and R.J. Hodrick (2000): Expectations hypotheses tests. NBER Working Paper 7609. Cambridge, Massachusetts.

Bekaert, G., R.J. Hodrick, and D.A. Marshall (1997): On biases in tests of the expectations hypothesis of the term structure of interest rates. Journal of Financial Economics 44, 309-348.

Bose, A. (1988): Edgeworth correction by bootstrap in autoregressions. Annals of Statistics 16, 1709-1722.

Campbell, J.Y. (1991): A variance decomposition for stock returns. Economic Journal 101, 157-179.

Campbell, J.Y. (1999): Asset prices, consumption, and the business cycle. In: J.B. Taylor and M. Woodford (eds.), Handbook of Macroeconomics, North-Holland.

Campbell, J.Y. and J. Ammer (1993): What moves the stock and bond markets? A variance decomposition for long-term asset returns. Journal of Finance 48, 3-37.

Campbell, J.Y. and R.J. Shiller (1987): Cointegration and test of present value models. Journal of Political Economy 95, 1062-1088.

Campbell, J.Y. and R.J. Shiller (1988): The dividend-price ratio and expectations of future dividends and discount factors. Review of Financial Studies 1, 195-228.

Campbell, J.Y., A.W. Lo, and A.C. MacKinlay (1997): The Econometrics of Financial Markets. Princeton University Press, New Jersey.

Durlauf, S. and R.E. Hall (1989): Bounds on the variances of specification errors in models with expectations. NBER Working Paper no. 2936. Cambridge, Massachusetts.

Engsted, T. (1995): Does the long-term interest rate predict future inflation? A multi-country analysis. Review of Economics and Statistics 77, 42-54. 
Engsted, T. (1998): Money demand during hyperinflation: Cointegration, rational expectations, and the importance of money demand shocks. Journal of Macroeconomics 20, 533-552.

Engsted, T. and N. Haldrup (1999): Estimating the LQAC model with I(2) variables. Journal of Applied Econometrics 14, 155-170.

Engsted, T. and C. Tanggaard (1994): A cointegration analysis of Danish zero-coupon bond yields. Applied Financial Economics 4, 265-278.

Engsted, T., E. Mammen, and C. Tanggaard (2000): Evaluating the C-CAPM and the Equity Premium Puzzle at short and long horizons: A Markovian bootstrap approach. Working Paper, The Aarhus School of Business (available at www.asb.dk/ ${ }^{\sim}$ tom).

Jorion, P. and W.N. Goetzmann (1999): Global stock markets in the Twentieth Century. Journal of Finance 54, 953-980.

Kilian, L. (1998): Small-sample confidence intervals for impulse response functions. Review of Economics and Statistics 80, 218-230.

Kærgård, N. (1991): Økonomisk Vakst: En Økonometrisk Analyse af Danmark 1870-1981. [Economic Growth: An Econometric Analysis of Denmark 1870-1981]. Jurist- og Økonomforbundets Forlag, Copenhagen.

Lund, J. and T. Engsted (1996): GMM and present value tests of the CCAPM: Evidence from the Danish, German, Swedish, and UK stock markets. Journal of International Money and Finance 15, 497-521.

Mishkin, F.S. (1990): The information in the longer maturity term structure about future inflation. Quarterly Journal of Economics 55, 815-828.

Patelis, A.D. (1997): Stock return predictability and the role of monetary policy. Journal of Finance 52, 1951-1972.

Shiller, R.J. and A.E. Beltratti (1992): Stock prices and bond yields: Can their comovements be explained in terms of present value models? Journal of Monetary Economics 30, 25-46. 


\section{Appendix}

\subsection{Appendix 1}

Derivation of equations (3) and (4) in section 2:

The approximate (linearized) log one-period gross return from $t$ to $t+1$ on a consol is (see Shiller and Beltratti, 1992)

$$
b_{t+1}=y_{t}-\rho_{b} y_{t+1}+k_{b}
$$

where $y_{t}$ is the $\log$ consol yield at time $t, \rho_{b}=\exp (-\bar{Y}), \bar{Y}$ is the mean nominal consol yield over the sample, and $k_{b}=-\rho_{b} \log \left(\rho_{b}\right)-\left(1-\rho_{b}\right) \log (1-$ $\left.\rho_{b}\right)$ is a constant arising from the linearization. Abstracting from $k_{b}$, this expression can be solved recursively forward to give

$$
y_{t}=\sum_{j=0}^{\infty} \rho_{b}^{j} b_{t+j+1}
$$

Inserting the definition of the excess bond return, $x_{t+1} \equiv b_{t+1}-i_{t}$, into this formula, results in:

$$
y_{t}=\sum_{j=0}^{\infty} \rho_{b}^{j}\left(i_{t+j}+x_{t+j+1}\right)
$$

This expression can also be written as

$$
\left(1-\rho_{b}\right) y_{t}=E_{t}\left(i_{t}+\rho_{b} i_{t+1}+\rho_{b}^{2} i_{t+2}+\ldots . . \rho_{b} i_{t}-\rho_{b}^{2} i_{t+1}-\ldots .\right)+\left(1-\rho_{b}\right) \sum_{j=0}^{\infty} \rho_{b}^{j} x_{t+j+1}
$$

from which equation (3) in section 2 follows immediately.

From combining (A1) and (A2) it follows that

$$
b_{t+1}-E_{t} b_{t+1}=-\left(E_{t+1}-E_{t}\right) \sum_{j=1}^{\infty} \rho_{b}^{j} b_{t+j+1}
$$

Inserting the definition of the excess bond return, $x_{t+1} \equiv b_{t+1}-\pi_{t+1}-r_{t+1}$, into this formula, results in equation (4) in section 2 . 


\subsection{Appendix 2}

Computing the unexpected excess bond return and the revisions of expectations of future inflation from Campbell and Ammer's (1993) VAR model:

In Campbell and Ammer (1993) the VAR model does not include the excess bond return directly; instead $z_{t}$ includes $\Delta i_{t}$ and the interest rate spread, $S_{t}$, i.e. $z_{t}=\left[e_{t}, r_{t}, \Delta i_{t}, S_{t}, \delta_{t}\right]^{\prime}$. From this model, and with the long coupon bond we work with in this paper, it follows that

$$
\begin{gathered}
\widetilde{x}_{t+1}=-\frac{\rho_{b}}{1-\rho_{b}}\left(e 3^{\prime}+e 4^{\prime}\right) \omega_{t+1} \\
\widetilde{x}_{r, t+1}=\rho_{b} e 2^{\prime} A\left(I-\rho_{b} A\right)^{-1} \omega_{t+1}
\end{gathered}
$$

However, in calculating $\widetilde{x}_{\pi, t+1}$ in the way Campbell and Ammer do it we run into problems. First note that $\pi_{t+j}=i_{t+j-1}-r_{t+j}$. Thus, $\widetilde{x}_{\pi, t+1}=$ $\left(E_{t+1}-E_{t}\right) \sum_{j=1}^{\infty} \rho_{b}^{j}\left(i_{t+j}-r_{t+j+1}\right)=-\widetilde{x}_{r, t+1}+\left(E_{t+1}-E_{t}\right) \sum_{j=1}^{\infty} \rho_{b}^{j} i_{t+j}$. Hence, since the third variable in the VAR is the first-difference of $i_{t}$, it follows that

$$
\widetilde{x}_{\pi, t+1}=-\widetilde{x}_{r, t+1}+\rho_{b} e 3^{\prime} \sum_{j=1}^{\infty} \rho_{b}^{j-1}(I+A)^{j-1} \omega_{t+1}
$$

The matrix $(I+A)$ will have unstable roots and, hence, in general the sum on the right-hand side of this expression will not converge. Campbell and Ammer do not face this problem because they work with an $n$-period zerocoupon bond such that the summation is of the form $\sum_{j=1}^{n-1}(I+A)^{j-1}$ which for finite $n$ has a well-defined tractable expression. We circumvent this problem by including the excess bond return directly in the VAR along with the real interest rate. This means that simple expressions exist for $\widetilde{x}_{t+1}, \widetilde{x}_{r, t+1}$, and $\widetilde{x}_{x, t+1}$ (see section 3.4 ), whereby $\widetilde{x}_{\pi, t+1}$ can be obtained as a residual from equation (17).

\subsection{Appendix 3}

Insert Tables A1 to A6. 


\begin{tabular}{|c|c|c|}
\hline & \multicolumn{2}{|l|}{ 1922-1996 } \\
\hline & $\operatorname{VAR}(1)$ & $\operatorname{VAR}(2)$ \\
\hline $\operatorname{Corr}\left(\delta, \delta^{\prime}\right)$ & $\mathbf{0 . 9 6 5}(0.124)[0.634,0.998]$ & $\mathbf{0 . 9 6 9}(0.346)[-0.391,0.988]$ \\
\hline $\mathrm{V}\left(\delta^{\prime}\right) / \mathrm{V}(\delta)$ & $\mathbf{0 . 4 8 5}(0.517)[0.094,1.912]$ & $\mathbf{0 . 2 8 2}(0.663)[0.063,1.252]$ \\
\hline$N R_{\delta}$ & $\mathbf{0 . 1 4 1}(0.236)[0.014,0.725]$ & $\mathbf{0 . 2 5 3}(0.765)[0.051,1.730]$ \\
\hline $\operatorname{Corr}\left(e, e^{\prime}\right)$ & $\mathbf{0 . 8 3 7}(0.196)[0.248,0.976]$ & $\mathbf{0 . 7 2 5}(0.211)[0.107,0.895]$ \\
\hline $\mathrm{V}\left(e^{\prime}\right) / \mathrm{V}(e)$ & $\mathbf{0 . 5 5 4}(0.439)[0.318,1.682]$ & $\mathbf{0 . 4 6 8}(0.525)[0.246,1.627]$ \\
\hline$N R_{e}$ & $\mathbf{0 . 3 0 8}(0.382)[0.062,1.276]$ & $\mathbf{0 . 4 7 6}(0.618)[0.228,2.070]$ \\
\hline $\operatorname{Corr}\left(S, S^{\prime}\right)$ & $\mathbf{0 . 9 0 5}(0.198)[0.277,0.995]$ & $\mathbf{0 . 8 6 5}(0.207)[0.196,0.972]$ \\
\hline $\mathrm{V}\left(S^{\prime}\right) / \mathrm{V}(S)$ & $\mathbf{0 . 9 6 5}(15.08)[0.399,4.488]$ & $1.591(1.633)[0.577,6.452]$ \\
\hline$N R_{S}$ & $\mathbf{0 . 1 8 8}(14.94)[0.021,3.434]$ & $0.408(1.314)[0.111,4.494]$ \\
\hline $\operatorname{Corr}\left(x, x^{\prime}\right)$ & $\mathbf{0 . 8 8 0}(0.120)[0.527,0.975]$ & $\mathbf{0 . 5 6 5}(0.144)[0.193,0.750]$ \\
\hline $\mathrm{V}\left(x^{\prime}\right) / \mathrm{V}(x)$ & $1.159(3.583)[0.637,2.817]$ & $\mathbf{0 . 8 4 5}(0.575)[0.386,2.545]$ \\
\hline$N R_{x}$ & $\mathbf{0 . 2 6 5}(3.632)[0.055,1.780]$ & $\mathbf{0 . 8 0 6}(0.559)[0.458,2.566]$ \\
\hline $\operatorname{Corr}(\delta, S)$ & $\mathbf{0 . 1 9 5}(0.207)[-0.292,0.506]$ & $0.208(0.231)[-0.342,0.543]$ \\
\hline $\operatorname{Corr}\left(\delta^{\prime}, S^{\prime}\right)$ & $\mathbf{0 . 3 2 8}(0.408)[-0.590,0.895]$ & $\mathbf{0 . 3 9 8}(0.439)[-0.833,0.818]$ \\
\hline $\mathrm{V}(\delta) / \mathrm{V}(S)$ & $651.1(485.2)[250.4,2078]$ & $653.3(452.8)[234.4,1941]$ \\
\hline $\mathrm{V}\left(\delta^{\prime}\right) / \mathrm{V}\left(S^{\prime}\right)$ & $327.6(571.9)[38.68,1918]$ & $115.8(224.6)[16.01,728.6]$ \\
\hline $\operatorname{Corr}(e, x)$ & $\mathbf{0 . 4 7 5}(0.088)[0.279,0.623]$ & $\mathbf{0 . 4 3 9}(0.104)[0.208,0.613]$ \\
\hline $\operatorname{Corr}\left(e^{\prime}, x^{\prime}\right)$ & $\mathbf{0 . 3 3 1}(0.269)[-0.270,0.755]$ & $\mathbf{- 0 . 2 0 2}(0.331)[-0.763,0.477]$ \\
\hline $\mathrm{V}(e) / \mathrm{V}(x)$ & $2.291(0.718)[1.304,4.073]$ & $2.415(0.662)[1.479,40.22]$ \\
\hline $\mathrm{V}\left(e^{\prime}\right) / \mathrm{V}\left(x^{\prime}\right)$ & $1.096(0.859)[0.392,3.521]$ & $\mathbf{1 . 3 3 8}(1.324)[0.419,5.019]$ \\
\hline $\begin{array}{l}\text { LR test of } \\
\text { restrictions: }\end{array}$ & $11.006(0.201)$ & $47.696(0.000)$ \\
\hline
\end{tabular}

Notes: 'Corr $(\cdot)$ ', $\mathrm{V}(\cdot) / \mathrm{V}(\cdot)^{\prime}$ ', and 'NR' denote 'correlation-coefficient', 'variance ratio', and 'noise ratio', respectively. The numbers in bold are point estimates based on the bias-corrected VAR parameter estimates. The numbers in parentheses are bootstrap standard errors based on 100.000 bootstrap simulations. The numbers in brackets are bootstrap 95\% confidence intervals based on 100.000 bootstrap simulations. The LR statistics are $\chi^{2}$ distributed asymptotically, with 4 (the $\operatorname{VAR}(1)$ model) and 8 (the $\operatorname{VAR}(2)$ model) degrees of freedom, and with p-values in parentheses.

Table 1: Summary statistics from VAR systems based on the present value models, Denmark 1922-1996. 


\begin{tabular}{|c|c|c|}
\hline & \multicolumn{2}{|l|}{ 1922-1982 } \\
\hline & $\operatorname{VAR}(1)$ & $\operatorname{VAR}(2)$ \\
\hline $\operatorname{Corr}\left(\delta, \delta^{\prime}\right)$ & $\mathbf{0 . 9 8 1}(0.179)[0.328,0.996]$ & $\mathbf{0 . 9 6 9}(0.255)[0.024,0.980]$ \\
\hline $\mathrm{V}\left(\delta^{\prime}\right) / \mathrm{V}(\delta)$ & $\mathbf{0 . 4 5 1}(0.518)[0.178,1.851]$ & $\mathbf{0 . 3 8 0}(0.923)[0.164,2.486]$ \\
\hline$N R_{\delta}$ & $\mathbf{0 . 1 3 3}(0.454)[0.025,1.369]$ & $\mathbf{0 . 1 8 5}(1.028)[0.068,2.746]$ \\
\hline $\operatorname{Corr}\left(e, e^{\prime}\right)$ & $\mathbf{0 . 8 7 5}(0.169)[0.343,0.975]$ & $\mathbf{0 . 8 1 9}(0.156)[0.321,0.918]$ \\
\hline $\mathrm{V}\left(e^{\prime}\right) / \mathrm{V}(e)$ & $\mathbf{0 . 5 8 7}(0.337)[0.320,1.499]$ & $\mathbf{0 . 5 7 2}(0.524)[0.249,2.076]$ \\
\hline$N R_{e}$ & $\mathbf{0 . 2 4 6}(0.343)[0.062,1.273]$ & $\mathbf{0 . 3 3 3}(0.447)[0.180,1.693]$ \\
\hline $\operatorname{Corr}\left(S, S^{\prime}\right)$ & $\mathbf{0 . 9 9 3}(0.040)[0.876,0.999]$ & $\mathbf{0 . 9 6 2}(0.055)[0.793,0.988]$ \\
\hline $\mathrm{V}\left(S^{\prime}\right) / \mathrm{V}(S)$ & $1.072(0.634)[0.374,2.788]$ & $1.089(0.680)[0.408,2.987]$ \\
\hline$N R_{S}$ & $\mathbf{0 . 0 1 5}(0.164)[0.007,0.541]$ & $\mathbf{0 . 0 8 0}(0.199)[0.045,0.709]$ \\
\hline $\operatorname{Corr}\left(x, x^{\prime}\right)$ & $\mathbf{0 . 9 7 8}(0.089)[0.653,0.987]$ & $\mathbf{0 . 7 8 3}(0.127)[0.402,0.889]$ \\
\hline $\mathrm{V}\left(x^{\prime}\right) / \mathrm{V}(x)$ & $\mathbf{0 . 9 0 4}(0.298)[0.616,1.760]$ & $\mathbf{0 . 6 4 4}(0.347)[0.337,1.641]$ \\
\hline$N R_{x}$ & $\mathbf{0 . 0 4 4}(0.228)[0.028,0.851]$ & $\mathbf{0 . 3 8 7}(0.280)[0.224,1.296]$ \\
\hline $\operatorname{Corr}(\delta, S)$ & $\mathbf{0 . 2 4 0}(0.207)[-0.200,0.598]$ & $0.256(0.190)[-0.160,0.578]$ \\
\hline $\operatorname{Corr}\left(\delta^{\prime}, S^{\prime}\right)$ & $\mathbf{- 0 . 0 2 0}(0.482)[-0.916,0.775]$ & $0.005(0.501)[-0.939,0.756]$ \\
\hline $\mathrm{V}(\delta) / \mathrm{V}(S)$ & $\mathbf{3 3 1 . 1}(226.2)[131.8,986.4]$ & $334.6(214.1)[140.3,953.9]$ \\
\hline $\mathrm{V}\left(\delta^{\prime}\right) / \mathrm{V}\left(S^{\prime}\right)$ & $139.2(453.8)[31.14,1149]$ & $116.8(370.7)[31.60,1049]$ \\
\hline $\operatorname{Corr}(e, x)$ & $\mathbf{0 . 3 1 4}(0.113)[0.063,0.503]$ & $\mathbf{0 . 2 7 3}(0.109)[0.035,0.463]$ \\
\hline $\operatorname{Corr}\left(e^{\prime}, x^{\prime}\right)$ & $\mathbf{0 . 2 2 2}(0.229)[-0.289,0.600]$ & $\mathbf{- 0 . 1 1 2}(0.291)[-0.653,0.446]$ \\
\hline $\mathrm{V}(e) / \mathrm{V}(x)$ & $3.569(1.405)[1.752,7.101]$ & $\mathbf{3 . 6 0 0}(1.289)[1.747,6.661]$ \\
\hline $\mathrm{V}\left(e^{\prime}\right) / \mathrm{V}\left(x^{\prime}\right)$ & $2.319(1.698)[0.871,7.100]$ & $\mathbf{3 . 1 9 7}(3.679)[0.845,13.56]$ \\
\hline $\begin{array}{l}\text { LR test of } \\
\text { restrictions: }\end{array}$ & $5.086(0.748)$ & $22.768(0.120)$ \\
\hline
\end{tabular}

Table 2: Summary statistics from VAR systems based on the present value models, Denmark 1922-1982. 


\begin{tabular}{|c|c|c|}
\hline & \multicolumn{2}{|l|}{ 1947-1996 } \\
\hline & $\operatorname{VAR}(1)$ & $\operatorname{VAR}(2)$ \\
\hline $\operatorname{Corr}\left(\delta, \delta^{\prime}\right)$ & $\mathbf{- 0 . 1 4 7}(0.803)[-0.990,0.993]$ & $\mathbf{0 . 3 4 3}(0.556)[-0.865,0.959]$ \\
\hline $\mathrm{V}\left(\delta^{\prime}\right) / \mathrm{V}(\delta)$ & $\mathbf{0 . 0 1 0}(>9999)[0.008,2.486]$ & $\mathbf{0 . 3 8 9}(>9999)[0.067,7.634]$ \\
\hline$N R_{\delta}$ & $\mathbf{1 . 0 3 9}(>9999)[0.106,5.777]$ & $\mathbf{0 . 9 6 1}(>9999)[0.052,9.409]$ \\
\hline $\operatorname{Corr}\left(e, e^{\prime}\right)$ & $\mathbf{0 . 0 4 2}(0.474)[-0.743,0.888]$ & $\mathbf{0 . 0 9 5}(0.341)[-0.532,0.735]$ \\
\hline $\mathrm{V}\left(e^{\prime}\right) / \mathrm{V}(e)$ & $\mathbf{0 . 3 0 3}(>9999)[0.131,3.278]$ & $\mathbf{0 . 2 8 8}(>9999)[0.097,3.908]$ \\
\hline$N R_{e}$ & $\mathbf{1 . 2 5 7}(>9999)[0.286,6.210]$ & $\mathbf{1 . 1 8 6}(>9999)[0.527,5.804]$ \\
\hline $\operatorname{Corr}\left(S, S^{\prime}\right)$ & $\mathbf{0 . 6 0 5}(0.337)[-0.225,0.984]$ & $\mathbf{0 . 4 2 4}(0.413)[-0.520,0.942]$ \\
\hline $\mathrm{V}\left(S^{\prime}\right) / \mathrm{V}(S)$ & $\mathbf{1 . 8 6 7}(1496)[0.289,21.34]$ & $1.859(945.2)[0.450,18.54]$ \\
\hline$N R_{S}$ & $1.213(1495)[0.070,20.74]$ & $1.703(944.1)[0.219,18.45]$ \\
\hline $\operatorname{Corr}\left(x, x^{\prime}\right)$ & $\mathbf{0 . 8 1 0}(0.151)[0.370,0.950]$ & $\mathbf{0 . 5 1 4}(0.174)[0.050,0.718]$ \\
\hline $\mathrm{V}\left(x^{\prime}\right) / \mathrm{V}(x)$ & $1.745(275.2)[0.595,5.681]$ & $\mathbf{0 . 8 6 1}(143.7)[0.287,3.514]$ \\
\hline$N R_{x}$ & $0.605(275.0)[0.117,3.978]$ & $0.907(143.9)[0.513,3.664]$ \\
\hline $\operatorname{Corr}(\delta, S)$ & $\mathbf{0 . 2 4 9}(0.261)[-0.362,0.627]$ & $0.275(0.294)[-0.386,0.720]$ \\
\hline $\operatorname{Corr}\left(\delta^{\prime}, S^{\prime}\right)$ & $\mathbf{- 0 . 0 8 5}(0.747)[-0.992,0.979]$ & $\mathbf{0 . 1 4 2}(0.562)[-0.932,0.902]$ \\
\hline $\mathrm{V}(\delta) / \mathrm{V}(S)$ & $480.8(617.6)[127.1,2369]$ & $499.0(507.2)[137.9,2008]$ \\
\hline $\mathrm{V}\left(\delta^{\prime}\right) / \mathrm{V}\left(S^{\prime}\right)$ & $2.570(>9999)[1.204,510.1]$ & $104.5(>9999)[9.814,1649]$ \\
\hline $\operatorname{Corr}(e, x)$ & $\mathbf{0 . 4 9 7}(0.115)[0.216,0.666]$ & $\mathbf{0 . 4 4 3}(0.122)[0.164,0.642]$ \\
\hline $\operatorname{Corr}\left(e^{\prime}, x^{\prime}\right)$ & $\mathbf{- 0 . 2 3 3}(0.471)[-0.880,0.764]$ & $\mathbf{- 0 . 3 1 8}(0.471)[-0.887,0.765]$ \\
\hline $\mathrm{V}(e) / \mathrm{V}(x)$ & $\mathbf{2 . 2 1 5}(0.806)[1.152,4.248]$ & $\mathbf{2 . 1 7 2}(0.638)[1.271,3.724]$ \\
\hline $\mathrm{V}\left(e^{\prime}\right) / \mathrm{V}\left(x^{\prime}\right)$ & $\mathbf{0 . 3 8 5}(>9999)[0.113,3.094]$ & $\mathbf{0 . 7 2 7}(>9999)[0.151,8.906]$ \\
\hline $\begin{array}{l}\text { LR test of } \\
\text { restrictions: }\end{array}$ & $14.004(0.082)$ & $46.964(0.000)$ \\
\hline
\end{tabular}

Notes: See the notes to Table 1.

Table 3: Summary statistics from VAR systems based on the present value models, Denmark 1947-1996. 


\begin{tabular}{|c|c|c|}
\hline & \multicolumn{2}{|c|}{$1922-1996$} \\
& $\operatorname{VAR}(1)$ & $\operatorname{VAR}(2)$ \\
\hline Return $R^{2}$ & $(0.521)$ & 0.196 \\
& & $(0.000)$ \\
\hline Shares of: & & \\
$\operatorname{Var}\left(\widetilde{e}_{d}\right)$ & $\mathbf{0 . 8 8 4}(5.049)[0.410,4.738]$ & $\mathbf{0 . 9 7 8}(1.013)[0.529,3.730]$ \\
$\operatorname{Var}\left(\widetilde{e}_{r}\right)$ & $\mathbf{0 . 5 3 6}(6.890)[0.189,3.153]$ & $\mathbf{0 . 6 1 2}(4.074)[0.210,3.493]$ \\
$\operatorname{Var}\left(\widetilde{e}_{e}\right)$ & $\mathbf{0 . 2 6 8}(22.08)[0.039,1.694]$ & $\mathbf{0 . 4 3 8}(2.837)[0.097,2.618]$ \\
$-2 \operatorname{Cov}\left(\widetilde{e}_{d}, \widetilde{e}_{r}\right)$ & $\mathbf{- 0 . 9 0 7}(11.29)[-6.165,-0.066]$ & $\mathbf{- 0 . 9 4 3}(2.193)[-5.341,0.003]$ \\
$-2 \operatorname{Cov}\left(\widetilde{e}_{d}, \widetilde{e}_{e}\right)$ & $\mathbf{0 . 8 1 6}(19.90)[-1.487,2.264]$ & $\mathbf{0 . 4 5 9}(1.612)[-1.633,1.790]$ \\
$2 \operatorname{Cov}\left(\widetilde{e}_{r}, \widetilde{e}_{e}\right)$ & $\mathbf{- 0 . 5 9 6}(24.20)[-3.313,0.413]$ & $\mathbf{- 0 . 5 4 3}(6.614)[-4.185,0.252]$ \\
\hline$R^{2}\left(\widetilde{e}_{d}\right)$ & $\mathbf{0 . 7 9 5}(0.200)[0.190,0.959]$ & $\mathbf{0 . 5 5 3}(0.194)[0.080,0.818]$ \\
$R^{2}\left(\widetilde{e}_{r}\right)$ & $\mathbf{0 . 1 5 1}(0.144)[-0.010,0.515]$ & $\mathbf{0 . 1 3 0}(0.139)[-0.016,0.486]$ \\
$R^{2}\left(\widetilde{e}_{e}\right)$ & $\mathbf{0 . 0 5 1}(0.174)[-0.015,0.652]$ & $\mathbf{0 . 3 1 4}(0.209)[0.050,0.828]$ \\
\hline
\end{tabular}

Note: The numbers in parentheses under "Return $R^{2}$ " are joint significance of the explanatory variables in the $e_{t}$ regressions. The numbers in bold are point estimates based on the bias-corrected VAR parameter estimates. The numbers in parentheses are bootstrap standard errors based on 100.000 bootstrap simulations. The numbers in brackets are bootstrap 95\% confidence intervals based on 100.000 bootstrap simulations.

Table 4: Variance decomposition for excess stock returns, Denmark 1922-1996. 


\begin{tabular}{|c|c|c|}
\hline & \multicolumn{2}{|c|}{$1922-1982$} \\
& $\operatorname{VAR}(1)$ & $\operatorname{VAR}(2)$ \\
\hline Return $R^{2}$ & 0.102 & 0.158 \\
& $(0.397)$ & $(0.137)$ \\
\hline Shares of: & & \\
$\operatorname{Var}\left(\widetilde{e}_{d}\right)$ & $\mathbf{0 . 7 5 6}(0.484)[0.415,2.166]$ & $\mathbf{0 . 8 9 4}(532.8)[0.554,4.029]$ \\
$\operatorname{Var}\left(\widetilde{e}_{r}\right)$ & $\mathbf{0 . 4 9 1}(0.528)[0.153,2.054]$ & $\mathbf{0 . 6 1 8}(232.4)[0.179,3.528]$ \\
$\operatorname{Var}\left(\widetilde{e}_{e}\right)$ & $\mathbf{0 . 2 3 3}(0.240)[0.062,0.937]$ & $\mathbf{0 . 3 4 4}(83.05)[0.101,2.693]$ \\
$-2 \operatorname{Cov}\left(\widetilde{e}_{d}, \widetilde{e}_{r}\right)$ & $\mathbf{- 0 . 6 2 9}(0.856)[-3.005,0.090]$ & $\mathbf{- 0 . 5 3 2}(697.6)[-4.856,0.788]$ \\
$-2 \operatorname{Cov}\left(\widetilde{e}_{d}, \widetilde{e}_{e}\right)$ & $\mathbf{0 . 3 7 3}(0.380)[-0.647,0.861]$ & $\mathbf{0 . 0 3 6}(377.0)[-3.397,0.798]$ \\
$2 \operatorname{Cov}\left(\widetilde{e}_{r}, \widetilde{e}_{e}\right)$ & $\mathbf{- 0 . 2 2 4}(0.535)[-1.656,0.395]$ & $\mathbf{- 0 . 3 6 0}(245.1)[-3.950,0.791]$ \\
\hline$R^{2}\left(\widetilde{e}_{d}\right)$ & $\mathbf{0 . 5 2 2}(0.234)[0.037,0.890]$ & $\mathbf{0 . 4 6 7}(0.226)[0.023,0.852]$ \\
$R^{2}\left(\widetilde{e}_{r}\right)$ & $\mathbf{0 . 2 9 5}(0.194)[-0.004,0.709]$ & $\mathbf{0 . 2 4 5}(0.195)[-0.024,0.675]$ \\
$R^{2}\left(\widetilde{e}_{e}\right)$ & $\mathbf{0 . 1 8 0}(0.168)[0.004,0.635]$ & $\mathbf{0 . 2 8 5}(0.175)[0.036,0.701]$ \\
\hline
\end{tabular}

Note: See the notes to Table 4.

Table 5: Variance decomposition for excess stock returns, Denmark 1922-1982. 


\begin{tabular}{|c|c|c|}
\hline & \multicolumn{2}{|l|}{$1947-1996$} \\
\hline & $\operatorname{VAR}(1)$ & $\operatorname{VAR}(2)$ \\
\hline Return $R^{2}$ & $\begin{array}{c}0.096 \\
(0.457) \\
\end{array}$ & $\begin{array}{c}0.310 \\
(0.000)\end{array}$ \\
\hline Shares of: & & \\
\hline $\operatorname{Var}\left(\widetilde{e}_{d}\right)$ & $\mathbf{0 . 5 2 1}(2820)[0.171,6.880]$ & $\mathbf{0 . 4 4 8}(27.11)[0.229,2.768]$ \\
\hline $\operatorname{Var}\left(\widetilde{e}_{r}\right)$ & $\mathbf{0 . 5 2 0}(3777)[0.079,7.496]$ & $\mathbf{0 . 4 7 8}(7.925)[0.101,3.555]$ \\
\hline $\operatorname{Var}\left(\widetilde{e}_{e}\right)$ & $\mathbf{0 . 6 6 5}(616.5)[0.067,5.623]$ & $\mathbf{1 . 7 5 3}(64.27)[0.577,8.288]$ \\
\hline$-2 \operatorname{Cov}\left(\widetilde{e}_{d}, \widetilde{e}_{r}\right)$ & $\mathbf{- 0 . 6 8 5}(6108)[-11.21,0.353]$ & $\mathbf{- 0 . 3 9 0}(28.88)[-3.704,1.639]$ \\
\hline$-2 \operatorname{Cov}\left(\widetilde{e}_{d}, \widetilde{e}_{e}\right)$ & $\mathbf{1 . 0 3 3}(1424)[-1.612,4.468]$ & $\mathbf{- 0 . 1 7 5}(83.25)[-6.145,1.242]$ \\
\hline $2 \operatorname{Cov}\left(\widetilde{e}_{r}, \widetilde{e}_{e}\right)$ & $\mathbf{- 1 . 0 5 4}(2429)[-10.61,0.514]$ & $\mathbf{- 1 . 1 1 4}(44.85)[-7.934,0.026]$ \\
\hline$R^{2}\left(\widetilde{e}_{d}\right)$ & $\mathbf{0 . 9 2 6}(0.218)[0.152,0.981]$ & $\mathbf{0 . 0 6 0}(0.132)[-0.026,0.450]$ \\
\hline$R^{2}\left(\widetilde{e}_{r}\right)$ & $\mathbf{0 . 0 3 8}(0.173)[-0.029,0.609]$ & $\mathbf{0 . 1 0 0}(0.104)[-0.040,0.345]$ \\
\hline$R^{2}\left(\widetilde{e}_{e}\right)$ & $\mathbf{0 . 0 3 2}(0.135)[-0.025,0.501]$ & $\mathbf{0 . 8 3 5}(0.132)[0.430,0.945]$ \\
\hline
\end{tabular}

Note: See the notes to Table 4.

Table 6: Variance decomposition for excess stock returns, Denmark 1947-1996. 


\begin{tabular}{|c|c|c|}
\hline & \multicolumn{2}{|c|}{$1922-1996$} \\
& $\operatorname{VAR}(1)$ & $\operatorname{VAR}(2)$ \\
\hline Return $R^{2}$ & $(0.271$ & 0.282 \\
& & $(0.000)$ \\
\hline Shares of: & & \\
$\operatorname{Var}\left(\widetilde{x}_{\pi}\right)$ & $\mathbf{3 . 9 2 2}(4.221)[1.303,14.97]$ & $\mathbf{4 . 6 8 2}(259.6)[1.670,20.19]$ \\
$\operatorname{Var}\left(\widetilde{x}_{r}\right)$ & $\mathbf{0 . 5 8 8}(0.814)[0.160,2.875]$ & $\mathbf{0 . 6 6 5}(21.04)[0.207,3.392]$ \\
$\operatorname{Var}\left(\widetilde{x}_{x}\right)$ & $\mathbf{0 . 6 7 0}(1.342)[0.122,4.319]$ & $\mathbf{0 . 7 3 6}(133.2)[0.123,5.912]$ \\
$2 \operatorname{Cov}\left(\widetilde{x}_{\pi}, \widetilde{x}_{r}\right)$ & $\mathbf{- 2 . 5 5 7}(3.537)[-11.88,-0.374]$ & $\mathbf{- 3 . 1 4 0}(147.4)[-15.47,-0.773]$ \\
$2 \operatorname{Cov}\left(\widetilde{x}_{\pi}, \widetilde{x}_{x}\right)$ & $\mathbf{- 2 . 5 3 2}(4.640)[-14.72,-0.014]$ & $\mathbf{- 3 . 0 6 9}(371.7)[-20.57,-0.261]$ \\
$2 \operatorname{Cov}\left(\widetilde{x}_{r}, \widetilde{x}_{x}\right)$ & $\mathbf{0 . 9 1 0}(1.804)[-0.265,5.394]$ & $\mathbf{1 . 1 2 7}(105.4)[0.072,7.408]$ \\
\hline$R^{2}\left(\widetilde{x}_{\pi}\right)$ & $\mathbf{0 . 4 8 0}(0.151)[0.151,0.738]$ & $\mathbf{0 . 5 3 0}(0.146)[0.175,0.740]$ \\
$R^{2}\left(\widetilde{x}_{r}\right)$ & $\mathbf{0 . 3 4 8}(0.170)[0.045,0.698]$ & $\mathbf{0 . 3 3 8}(0.156)[0.078,0.687]$ \\
$R^{2}\left(\widetilde{x}_{x}\right)$ & $\mathbf{0 . 1 6 5}(0.126)[0.010,0.488]$ & $\mathbf{0 . 1 2 8}(0.102)[0.008,0.392]$ \\
\hline
\end{tabular}

Note: The numbers in parentheses under "Return $R^{2}$ " are joint significance of the explanatory variables in the $x_{t}$ regressions. The numbers in bold are point estimates based on the bias-corrected VAR parameter estimates. The numbers in parentheses are bootstrap standard errors based on 100.000 bootstrap simulations. The numbers in brackets are bootstrap 95\% confidence intervals based on 100.000 bootstrap simulations.

Table 7: Variance decomposition for excess bond returns, Denmark 1922-1996. 


\begin{tabular}{|c|c|c|}
\hline & \multicolumn{2}{|c|}{$1922-1982$} \\
& $\operatorname{VAR}(1)$ & $\operatorname{VAR}(2)$ \\
\hline Return $R^{2}$ & $(0.110$ & 0.227 \\
& & $(0.006)$ \\
\hline Shares of: & & \\
$\operatorname{Var}\left(\widetilde{x}_{\pi}\right)$ & $\mathbf{1 . 8 2 8}(1.352)[0.896,5.940]$ & $\mathbf{3 . 1 7 6}(94.86)[1.303,14.75]$ \\
$\operatorname{Var}\left(\widetilde{x}_{r}\right)$ & $\mathbf{0 . 5 5 7}(0.852)[0.137,3.194]$ & $\mathbf{1 . 0 2 9}(6.798)[0.264,6.562]$ \\
$\operatorname{Var}\left(\widetilde{x}_{x}\right)$ & $\mathbf{0 . 0 6 0}(0.232)[0.038,0.869]$ & $\mathbf{0 . 2 4 2}(59.04)[0.080,3.121]$ \\
$2 \operatorname{Cov}\left(\widetilde{x}_{\pi}, \widetilde{x}_{r}\right)$ & $\mathbf{- 1 . 3 2 2}(1.923)[-7.089,-0.073]$ & $\mathbf{- 2 . 9 8 9}(44.24)[-17.30,-0.547]$ \\
$2 \operatorname{Cov}\left(\widetilde{x}_{\pi}, \widetilde{x}_{x}\right)$ & $\mathbf{- 0 . 1 8 9}(0.933)[-3.021,0.571]$ & $\mathbf{- 1 . 0 3 2}(148.2)[-10.49,0.312]$ \\
$2 \operatorname{Cov}\left(\widetilde{x}_{r}, \widetilde{x}_{x}\right)$ & $\mathbf{0 . 0 6 6}(0.626)[-1.199,1.387]$ & $\mathbf{0 . 5 7 4}(33.30)[-1.294,4.737]$ \\
\hline$R^{2}\left(\widetilde{x}_{\pi}\right)$ & $\mathbf{0 . 6 2 9}(0.210)[0.099,0.883]$ & $\mathbf{0 . 4 2 7}(0.191)[0.017,0.728]$ \\
$R^{2}\left(\widetilde{x}_{r}\right)$ & $\mathbf{0 . 0 5 1}(0.180)[-0.037,0.617]$ & $\mathbf{0 . 2 5 8}(0.228)[-0.014,0.783]$ \\
$R^{2}\left(\widetilde{x}_{x}\right)$ & $\mathbf{0 . 3 1 8}(0.184)[0.024,0.721]$ & $\mathbf{0 . 3 1 3}(0.220)[0.011,0.812]$ \\
\hline
\end{tabular}

Note: See the notes to Table 7 .

Table 8: Variance decomposition for excess bond returns, Denmark 1922-1982. 


\begin{tabular}{|c|c|c|}
\hline & \multicolumn{2}{|c|}{$1947-1996$} \\
& $\operatorname{VAR}(1)$ & $\operatorname{VAR}(2)$ \\
\hline Return $R^{2}$ & $(0.376$ & 0.386 \\
& & $(0.000)$ \\
\hline Shares of: & & \\
$\operatorname{Var}\left(\widetilde{x}_{\pi}\right)$ & $\mathbf{5 . 0 8 6}(1176)[1.231,22.83]$ & $\mathbf{4 . 6 6 9}(3.106)[1.834,13.61]$ \\
$\operatorname{Var}\left(\widetilde{x}_{r}\right)$ & $\mathbf{0 . 5 5 8}(204.4)[0.096,3.072]$ & $\mathbf{0 . 4 7 6}(0.438)[0.115,1.760]$ \\
$\operatorname{Var}\left(\widetilde{x}_{x}\right)$ & $\mathbf{0 . 8 9 7}(399.1)[0.131,6.749]$ & $\mathbf{0 . 5 0 6}(0.757)[0.076,2.859]$ \\
$2 \operatorname{Cov}\left(\widetilde{x}_{\pi}, \widetilde{x}_{r}\right)$ & $\mathbf{- 3 . 1 9 5}(980.5)[-16.36,-0.513]$ & $\mathbf{- 2 . 8 5 0 ( 2 . 2 9 5 ) [ - 9 . 5 0 3 , - 0 . 8 1 0 ]}$ \\
$2 \operatorname{Cov}\left(\widetilde{x}_{\pi}, \widetilde{x}_{x}\right)$ & $\mathbf{3 . 7 1 3}(1370)[-24.07,-0.092]$ & $\mathbf{- 2 . 7 3 8}(3.126)[-12.00,-0.286]$ \\
$2 \operatorname{Cov}\left(\widetilde{x}_{r}, \widetilde{x}_{x}\right)$ & $\mathbf{1 . 3 6 7}(570.9)[0.107,8.782]$ & $\mathbf{0 . 9 3 7}(1.113)[0.098,4.246]$ \\
\hline$R^{2}\left(\widetilde{x}_{\pi}\right)$ & $\mathbf{0 . 5 2 0}(0.173)[0.144,0.809]$ & $\mathbf{0 . 7 5 1}(0.109)[0.474,0.898]$ \\
$R^{2}\left(\widetilde{x}_{r}\right)$ & $\mathbf{0 . 4 5 9}(0.176)[0.136,0.813]$ & $\mathbf{0 . 2 1 8}(0.105)[0.052,0.463]$ \\
$R^{2}\left(\widetilde{x}_{x}\right)$ & $\mathbf{0 . 0 1 0}(0.031)[-0.041,0.090]$ & $\mathbf{0 . 0 1 7}(0.027)[-0.053,0.059]$ \\
\hline
\end{tabular}

Note: See the notes to Table 7.

Table 9: Variance decomposition for excess bond returns, Denmark 1947-1996. 


\begin{tabular}{|c|c|c|c|c|c|c|c|}
\hline & $\widetilde{e}_{d}$ & $\widetilde{e}_{r}$ & $\widetilde{e}_{e}$ & $\widetilde{x}$ & $\widetilde{x}_{\pi}$ & $\widetilde{x}_{r}$ & $\widetilde{x}_{x}$ \\
\hline \multirow[t]{2}{*}{$\widetilde{e}$} & 0.891 & 0.295 & -0.730 & 0.542 & -0.542 & 0.305 & 0.363 \\
\hline & $(0.40)$ & $(0.35)$ & $(0.43)$ & $(0.52)$ & $(0.41)$ & $(0.25)$ & $(0.44)$ \\
\hline \multirow[t]{2}{*}{$\widetilde{e}_{d}$} & 1.000 & 0.659 & -0.837 & 0.522 & -0.692 & 0.646 & 0.433 \\
\hline & & $(0.27)$ & $(0.23)$ & $(0.35)$ & $(0.02)$ & $(0.18)$ & $(0.18)$ \\
\hline \multirow[t]{2}{*}{$\widetilde{e}_{r}$} & & 1.000 & -0.786 & 0.307 & -0.796 & 0.983 & 0.631 \\
\hline & & & $(0.14)$ & $(0.29)$ & $(0.28)$ & $(0.08)$ & $(0.16)$ \\
\hline \multirow[t]{2}{*}{$\widetilde{e}_{e}$} & & & 1.000 & -0.533 & 0.914 & -0.805 & -0.806 \\
\hline & & & & $(0.41)$ & $(0.25)$ & $(0.14)$ & $(0.23)$ \\
\hline \multirow[t]{2}{*}{$\widetilde{x}$} & & & & 1.000 & -0.695 & 0.307 & 0.173 \\
\hline & & & & & $(0.34)$ & $(0.25)$ & $(0.24)$ \\
\hline \multirow[t]{2}{*}{$\widetilde{x}_{\pi}$} & & $\operatorname{VAR}(1)$ & & & 1.000 & -0.842 & -0.781 \\
\hline & & $1922-1996$ & & & & $(0.20)$ & $(0.18)$ \\
\hline \multirow[t]{2}{*}{$\widetilde{x}_{r}$} & & & & & & 1.000 & $\mathbf{0 . 7 2 5}$ \\
\hline & & & & & & & \\
\hline
\end{tabular}

\begin{tabular}{c|ccccccc} 
& $\widetilde{e}_{d}$ & $\widetilde{e}_{r}$ & $\widetilde{e}_{e}$ & $\widetilde{x}$ & $\widetilde{x}_{\pi}$ & $\widetilde{x}_{r}$ & $\widetilde{x}_{x}$ \\
\hline$\widetilde{e}$ & $\mathbf{0 . 7 4 4}$ & $\mathbf{0 . 1 6 8}$ & $\mathbf{- 0 . 5 9 8}$ & $\mathbf{0 . 5 1 2}$ & $\mathbf{- 0 . 3 8 0}$ & $\mathbf{0 . 1 7 2}$ & $\mathbf{0 . 1 9 7}$ \\
& $(0.32)$ & $(0.32)$ & $(0.35)$ & $(0.35)$ & $(0.30)$ & $(0.19)$ & $(0.27)$ \\
$\widetilde{e}_{d}$ & 1.000 & $\mathbf{0 . 6 1 0}$ & $\mathbf{- 0 . 3 5 1}$ & $\mathbf{0 . 4 3 3}$ & $\mathbf{- 0 . 5 0 7}$ & $\mathbf{0 . 4 9 0}$ & $\mathbf{0 . 3 0 7}$ \\
& & $(0.21)$ & $(0.23)$ & $(0.23)$ & $(0.03)$ & $(0.16)$ & $(0.12)$ \\
$\widetilde{e}_{r}$ & & 1.000 & $\mathbf{- 0 . 5 2 5}$ & $\mathbf{0 . 3 9 1}$ & $\mathbf{- 0 . 8 4 6}$ & $\mathbf{0 . 9 6 7}$ & $\mathbf{0 . 7 5 9}$ \\
& & & $(0.16)$ & $(0.28)$ & $(0.23)$ & $(0.09)$ & $(0.17)$ \\
$\widetilde{e}_{e}$ & & & 1.000 & $\mathbf{- 0 . 5 8 9}$ & $\mathbf{0 . 8 1 8}$ & $\mathbf{- 0 . 6 7 2}$ & $\mathbf{- 0 . 7 3 6}$ \\
& & & & $(0.38)$ & $(0.27)$ & $(0.17)$ & $(0.29)$ \\
$\widetilde{x}$ & & & & 1.000 & $\mathbf{- 0 . 7 2 9}$ & $\mathbf{0 . 4 2 0}$ & $\mathbf{0 . 2 7 4}$ \\
& & & & & $(0.23)$ & $(0.23)$ & $(0.19)$ \\
$\widetilde{x}_{\pi}$ & & $\operatorname{VAR}(2)$ & & & 1.000 & $\mathbf{- 0 . 8 9 0}$ & $\mathbf{- 0 . 8 2 7}$ \\
& & $1922-1996$ & & & & $(0.18)$ & $(0.12)$ \\
$\widetilde{x}_{r}$ & & & & & & 1.000 & $\mathbf{0 . 8 0 5}$ \\
& & & & & & $(0.11)$ \\
\hline
\end{tabular}

Notes: The numbers in bold are correlation coefficients based on the bias-adjusted VAR parameter estimates. The numbers in parentheses are bootstrap standard errors based on 100.000 bootstrap simulations.

Table 10: Correlations among all the components in (10) and (11), Denmark 1922-1996. 


\begin{tabular}{|c|c|c|c|c|c|c|c|}
\hline & $\widetilde{e}_{d}$ & $\widetilde{e}_{r}$ & $\widetilde{e}_{e}$ & $\widetilde{x}$ & $\widetilde{x}_{\pi}$ & $\widetilde{x}_{r}$ & $\widetilde{x}_{x}$ \\
\hline \multirow[t]{2}{*}{$\widetilde{e}$} & 0.723 & -0.092 & -0.637 & 0.364 & -0.149 & -0.092 & -0.386 \\
\hline & $(0.39)$ & $(0.29)$ & $(0.31)$ & $(0.48)$ & $(0.42)$ & $(0.28)$ & $(0.36)$ \\
\hline \multirow[t]{2}{*}{$\widetilde{e}_{d}$} & 1.000 & 0.516 & -0.445 & 0.429 & -0.465 & 0.451 & -0.564 \\
\hline & & $(0.22)$ & $(0.24)$ & $(0.51)$ & $(0.05)$ & $(0.18)$ & $(0.21)$ \\
\hline \multirow[t]{2}{*}{$\widetilde{e}_{r}$} & & 1.000 & -0.332 & 0.073 & -0.601 & 0.971 & 0.061 \\
\hline & & & $(0.19)$ & $(0.43)$ & $(0.30)$ & $(0.11)$ & $(0.24)$ \\
\hline \multirow[t]{2}{*}{$\widetilde{e}_{e}$} & & & 1.000 & -0.087 & 0.344 & -0.408 & -0.304 \\
\hline & & & & $(0.42)$ & $(0.28)$ & $(0.17)$ & $(0.20)$ \\
\hline \multirow[t]{2}{*}{$\widetilde{x}$} & & & & 1.000 & -0.794 & 0.095 & 0.008 \\
\hline & & & & & $(0.52)$ & $(0.35)$ & $(0.40)$ \\
\hline \multirow[t]{2}{*}{$\widetilde{x}_{\pi}$} & & $\operatorname{VAR}(1)$ & & & 1.000 & -0.655 & -0.286 \\
\hline & & 1922-1982 & & & & $(0.26)$ & $(0.22)$ \\
\hline \multirow[t]{2}{*}{$\widetilde{x}_{r}$} & & & & & & 1.000 & $\begin{array}{r}\mathbf{0 . 1 8 0} \\
(0.16)\end{array}$ \\
\hline & $\widetilde{e}_{d}$ & $\widetilde{e}_{r}$ & $\widetilde{e}_{e}$ & $\widetilde{x}$ & $\widetilde{x}_{\pi}$ & $\widetilde{x}_{r}$ & $\widetilde{x}_{x}$ \\
\hline \multirow[t]{2}{*}{$\widetilde{e}$} & 0.684 & -0.219 & -0.310 & 0.349 & 0.104 & -0.268 & -0.535 \\
\hline & $(0.42)$ & $(0.25)$ & $(0.33)$ & $(0.34)$ & $(0.41)$ & $(0.22)$ & $(0.27)$ \\
\hline \multirow[t]{2}{*}{$\widetilde{e}_{d}$} & 1.000 & 0.358 & -0.033 & 0.115 & -0.039 & 0.160 & -0.424 \\
\hline & & $(0.19)$ & $(0.34)$ & $(0.43)$ & $(0.05)$ & $(0.21)$ & $(0.18)$ \\
\hline \multirow[t]{2}{*}{$\widetilde{e}_{r}$} & & 1.000 & -0.390 & 0.126 & -0.751 & 0.954 & 0.497 \\
\hline & & & $(0.19)$ & $(0.27)$ & $(0.23)$ & $(0.10)$ & $(0.21)$ \\
\hline \multirow[t]{2}{*}{$\widetilde{e}_{e}$} & & & 1.000 & -0.579 & 0.766 & -0.563 & -0.437 \\
\hline & & & & $(0.35)$ & $(0.38)$ & $(0.21)$ & $(0.34)$ \\
\hline \multirow[t]{2}{*}{$\widetilde{x}$} & & & & 1.000 & -0.654 & 0.176 & -0.027 \\
\hline & & & & & $(0.43)$ & $(0.30)$ & $(0.32)$ \\
\hline \multirow[t]{2}{*}{$\widetilde{x}_{\pi}$} & & $\operatorname{VAR}(2)$ & & & 1.000 & -0.827 & -0.589 \\
\hline & & 1922-1982 & & & & $(0.25)$ & $(0.18)$ \\
\hline \multirow[t]{2}{*}{$\widetilde{x}_{r}$} & & & & & & 1.000 & 0.576 \\
\hline & & & & & & & $(0.18)$ \\
\hline
\end{tabular}

Notes: See the notes to Table 10.

Table 11: Correlations among all the components in (10) and (11), Denmark 1922-1982. 


\begin{tabular}{|c|c|c|c|c|c|c|c|}
\hline & $\widetilde{e}_{d}$ & $\widetilde{e}_{r}$ & $\widetilde{e}_{e}$ & $\widetilde{x}$ & $\widetilde{x}_{\pi}$ & $\widetilde{x}_{r}$ & $\widetilde{x}_{x}$ \\
\hline \multirow[t]{2}{*}{$\widetilde{e}$} & 0.963 & 0.484 & -0.803 & 0.596 & -0.524 & 0.439 & 0.273 \\
\hline & $(0.40)$ & $(0.29)$ & $(0.44)$ & $(0.48)$ & $(0.40)$ & $(0.24)$ & $(0.39)$ \\
\hline \multirow[t]{2}{*}{$\widetilde{e}_{d}$} & 1.000 & 0.658 & -0.877 & 0.640 & -0.671 & 0.615 & 0.436 \\
\hline & & $(0.28)$ & $(0.40)$ & $(0.22)$ & $(0.11)$ & $(0.18)$ & $(0.14)$ \\
\hline \multirow{2}{*}{$\widetilde{e}_{r}$} & & 1.000 & -0.896 & 0.516 & -0.952 & 0.992 & 0.940 \\
\hline & & & $(0.18)$ & $(0.39)$ & $(0.27)$ & $(0.09)$ & $(0.21)$ \\
\hline \multirow[t]{2}{*}{$\widetilde{e}_{e}$} & & & 1.000 & -0.621 & 0.892 & -0.872 & -0.779 \\
\hline & & & & $(0.52)$ & $(0.42)$ & $(0.20)$ & $(0.38)$ \\
\hline \multirow[t]{2}{*}{$\widetilde{x}$} & & & & 1.000 & -0.723 & 0.476 & 0.291 \\
\hline & & & & & $(0.17)$ & $(0.30)$ & $(0.23)$ \\
\hline \multirow[t]{2}{*}{$\widetilde{x}_{\pi}$} & & $\operatorname{VAR}(1)$ & & & 1.000 & -0.948 & -0.869 \\
\hline & & 1947-1996 & & & & $(0.19)$ & $(0.09)$ \\
\hline \multirow[t]{2}{*}{$\widetilde{x}_{r}$} & & & & & & 1.000 & $\begin{array}{c}\mathbf{0 . 9 6 6} \\
(0.13)\end{array}$ \\
\hline & $\widetilde{e}_{d}$ & $\widetilde{e}_{r}$ & $\widetilde{e}_{e}$ & $\widetilde{x}$ & $\widetilde{x}_{\pi}$ & $\widetilde{x}_{r}$ & $\widetilde{x}_{x}$ \\
\hline \multirow[t]{2}{*}{$\widetilde{e}$} & 0.247 & 0.397 & -0.837 & 0.552 & -0.414 & 0.348 & 0.144 \\
\hline & $(0.24)$ & $(0.09)$ & $(0.38)$ & $(0.29)$ & $(0.23)$ & $(0.15)$ & $(0.21)$ \\
\hline \multirow[t]{2}{*}{$\widetilde{e}_{d}$} & 1.000 & 0.421 & 0.099 & 0.434 & -0.353 & 0.337 & 0.134 \\
\hline & & $(0.13)$ & $(0.46)$ & $(0.19)$ & $(0.02)$ & $(0.10)$ & $(0.05)$ \\
\hline \multirow[t]{2}{*}{$\widetilde{e}_{r}$} & & 1.000 & -0.609 & 0.711 & -0.951 & 0.986 & 0.933 \\
\hline & & & $(0.32)$ & $(0.25)$ & $(0.13)$ & $(0.10)$ & $(0.13)$ \\
\hline \multirow[t]{2}{*}{$\widetilde{e}_{e}$} & & & 1.000 & -0.569 & 0.631 & -0.607 & -0.528 \\
\hline & & & & $(0.50)$ & $(0.46)$ & $(0.34)$ & $(0.45)$ \\
\hline \multirow[t]{2}{*}{$\widetilde{x}$} & & & & 1.000 & -0.868 & 0.696 & 0.554 \\
\hline & & & & & $(0.16)$ & $(0.21)$ & $(0.17)$ \\
\hline \multirow[t]{2}{*}{$\widetilde{x}_{\pi}$} & & $\operatorname{VAR}(2)$ & & & 1.000 & -0.956 & -0.890 \\
\hline & & 1947-1996 & & & & $(0.12)$ & $(0.04)$ \\
\hline$\widetilde{x}_{r}$ & & & & & & 1.000 & 0.954 \\
\hline & & & & & & & $(0.06)$ \\
\hline
\end{tabular}

Notes: See the notes to Table 10.

Table 12: Correlations among all the components in (10) and (11), Denmark 1947-1996. 


\begin{tabular}{c|cccc} 
& \multicolumn{4}{|c}{$\operatorname{VAR}(1)$} \\
& $\delta_{t+1}$ & $i_{t+1}-\Delta d_{t+1}$ & $S_{t+1}$ & $\Delta i_{t+1}$ \\
\hline$\delta_{t}$ & 0.919 & 0.079 & -0.001 & 0.006 \\
$i_{t}-\Delta d_{t}$ & $(0.066)$ & $(0.037)$ & $(0.004)$ & $(0.004)$ \\
\multirow{3}{*}{$S_{t}$} & -0.340 & 0.269 & 0.002 & -0.010 \\
$\Delta i_{t}$ & $(0.193)$ & $(0.108)$ & $(0.011)$ & $(0.011)$ \\
& -0.068 & -1.365 & 0.678 & 0.339 \\
& $(1.799)$ & $(1.033)$ & $(0.095)$ & $(0.095)$ \\
& -3.210 & 1.174 & -0.090 & -0.026 \\
& $(2.027)$ & $(1.173)$ & $(0.111)$ & $(0.109)$
\end{tabular}

\begin{tabular}{c|cccc} 
& \multicolumn{4}{|c}{$\operatorname{VAR}(2)$} \\
& $\delta_{t+1}$ & $i_{t+1}-\Delta d_{t+1}$ & $S_{t+1}$ & $\Delta i_{t+1}$ \\
\hline$\delta_{t}$ & 0.673 & 0.244 & -0.007 & -0.008 \\
$i_{t}-\Delta d_{t}$ & $(0.163)$ & $(0.098)$ & $(0.009)$ & $(0.009)$ \\
& -0.553 & 0.382 & -0.007 & -0.022 \\
$S_{t}$ & $(0.254)$ & $(0.147)$ & $(0.014)$ & $(0.014)$ \\
& 3.200 & -3.164 & 0.355 & 0.596 \\
$\Delta i_{t}$ & $(3.339)$ & $(1.960)$ & $(0.182)$ & $(0.187)$ \\
& -0.808 & -0.325 & -0.419 & 0.192 \\
$\delta_{t-1}$ & $(3.375)$ & $(1.980)$ & $(0.187)$ & $(0.189)$ \\
$i_{t-1}-\Delta d_{t-1}$ & & & & \\
& 0.209 & -0.186 & 0.008 & 0.013 \\
$S_{t-1}$ & $(0.164)$ & $(0.098)$ & $(0.009)$ & $(0.010)$ \\
& -0.284 & 0.175 & -0.007 & -0.010 \\
$\Delta i_{t-1}$ & $(0.202)$ & $(0.114)$ & $(0.011)$ & $(0.011)$ \\
& -3.335 & 2.626 & 0.465 & -0.337 \\
& $(3.701)$ & $(2.174)$ & $(0.202)$ & $(0.206)$ \\
& 3.212 & 1.491 & 0.155 & -0.052 \\
& $(2.052)$ & $(1.200)$ & $0.107)$ & $(0.110)$ \\
\hline
\end{tabular}

Notes: The table reports bias-adjusted VAR parameter estimates with standard errors in parentheses, both based on 100.000 bootstrap simulations.

Table A1: Bias-adjusted VAR parameter estimates for the VAR model in section 3.3. Denmark 1922-1996. 


\begin{tabular}{c|cccc} 
& \multicolumn{4}{|c}{$\operatorname{VAR}(1)$} \\
& $\delta_{t+1}$ & $i_{t+1}-\Delta d_{t+1}$ & $S_{t+1}$ & $\Delta i_{t+1}$ \\
\hline$\delta_{t}$ & 0.681 & 0.235 & 0.002 & -0.003 \\
$i_{t}-\Delta d_{t}$ & $(0.102)$ & $(0.062)$ & $(0.005)$ & $(0.005)$ \\
\multirow{3}{*}{$S_{t}$} & -0.331 & 0.257 & -0.001 & -0.005 \\
$\Delta i_{t}$ & $(0.190)$ & $(0.112)$ & $(0.009)$ & $(0.010)$ \\
& 0.953 & -1.423 & 0.818 & 0.280 \\
& $(2.028)$ & $(1.194)$ & $(0.089)$ & $(0.098)$ \\
& 0.439 & 1.525 & -0.013 & 0.005 \\
& $(2.534)$ & $(1.532)$ & $(0.111)$ & $(0.121)$
\end{tabular}

\begin{tabular}{c|cccc} 
& \multicolumn{4}{|c}{$\operatorname{VAR}(2)$} \\
& $\delta_{t+1}$ & $i_{t+1}-\Delta d_{t+1}$ & $S_{t+1}$ & $\Delta i_{t+1}$ \\
\hline$\delta_{t}$ & 0.617 & 0.277 & -0.004 & -0.008 \\
$i_{t}-\Delta d_{t}$ & $(0.165)$ & $(0.110)$ & $(0.008)$ & $(0.009)$ \\
& -0.343 & 0.263 & -0.007 & -0.008 \\
$S_{t}$ & $(0.270)$ & $(0.167)$ & $(0.012)$ & $(0.014)$ \\
& 5.197 & -2.309 & 0.776 & 0.338 \\
$\Delta i_{t}$ & $(4.744)$ & $(2.951)$ & $(0.211)$ & $(0.234)$ \\
& 3.395 & 0.979 & -0.021 & 0.021 \\
$\delta_{t-1}$ & $(4.287)$ & $(2.651)$ & $(0.191)$ & $(0.207)$ \\
$i_{t-1}-\Delta d_{t-1}$ & 0.012 & -0.036 & 0.007 & 0.006 \\
& $(0.183)$ & $(0.120)$ & $(0.009)$ & $(0.009)$ \\
$S_{t-1}$ & -0.227 & 0.143 & -0.010 & -0.005 \\
& $(0.201)$ & $(0.122)$ & $(0.009)$ & $(0.010)$ \\
$\Delta i_{t-1}$ & -4.708 & 1.013 & 0.029 & -0.064 \\
& $(5.210)$ & $(3.239)$ & $(0.230)$ & $(0.255)$ \\
& 3.211 & 0.010 & 0.189 & -0.232 \\
& $(2.605)$ & $(1.635)$ & $0.110)$ & $(0.119)$ \\
\hline
\end{tabular}

Notes: The table reports bias-adjusted VAR parameter estimates with standard errors in parentheses, both based on 100.000 bootstrap simulations.

Table A2: Bias-adjusted VAR parameter estimates for the VAR model in section 3.3. Denmark 1922-1982. 


\begin{tabular}{c|cccc} 
& \multicolumn{4}{|c}{$\operatorname{VAR}(1)$} \\
& $\delta_{t+1}$ & $i_{t+1}-\Delta d_{t+1}$ & $S_{t+1}$ & $\Delta i_{t+1}$ \\
\hline$\delta_{t}$ & 0.989 & -0.019 & 0.001 & 0.008 \\
$i_{t}-\Delta d_{t}$ & $(0.077)$ & $(0.031)$ & $(0.006)$ & $(0.005)$ \\
\multirow{3}{*}{$S_{t}$} & 0.098 & 0.201 & 0.018 & -0.025 \\
$\Delta i_{t}$ & $(0.369)$ & $(0.142)$ & $(0.026)$ & $(0.024)$ \\
& 0.289 & -0.064 & 0.685 & 0.267 \\
& $(1.900)$ & $(0.742)$ & $(0.124)$ & $(0.114)$ \\
& -3.422 & 2.129 & -0.079 & -0.090 \\
& $(2.240)$ & $(0.915)$ & $(0.151)$ & $(0.139)$
\end{tabular}

\begin{tabular}{c|cccc} 
& \multicolumn{4}{|c}{$\operatorname{VAR}(2)$} \\
& $\delta_{t+1}$ & $i_{t+1}-\Delta d_{t+1}$ & $S_{t+1}$ & $\Delta i_{t+1}$ \\
\hline$\delta_{t}$ & 0.748 & 0.038 & -0.013 & -0.010 \\
$i_{t}-\Delta d_{t}$ & $(0.200)$ & $(0.070)$ & $(0.014)$ & $(0.014)$ \\
& -0.147 & 0.001 & -0.015 & -0.032 \\
$S_{t}$ & $(0.410)$ & $(0.136)$ & $(0.027)$ & $(0.027)$ \\
& 3.853 & -1.663 & 0.411 & 0.560 \\
$\Delta i_{t}$ & $(3.433)$ & $(1.155)$ & $(0.231)$ & $(0.227)$ \\
& -1.223 & 1.441 & -0.374 & 0.131 \\
$\delta_{t-1}$ & $(3.459)$ & $(1.162)$ & $(0.233)$ & $(0.228)$ \\
$i_{t-1}-\Delta d_{t-1}$ & 0.160 & -0.066 & 0.014 & 0.016 \\
& $(0.185)$ & $(0.066)$ & $(0.013)$ & $(0.013)$ \\
$S_{t-1}$ & -0.737 & 0.574 & -0.004 & -0.028 \\
$\Delta i_{t-1}$ & $(0.383)$ & $(0.123)$ & $(0.025)$ & $(0.024)$ \\
& -3.591 & 2.276 & 0.449 & -0.360 \\
& $(3.435)$ & $(1.161)$ & $(0.230)$ & $(0.224)$ \\
& 2.364 & 2.696 & 0.192 & -0.048 \\
& $(2.357)$ & $(0.767)$ & $0.149)$ & $(0.148)$ \\
\hline
\end{tabular}

Notes: The table reports bias-adjusted VAR parameter estimates with standard errors in parentheses, both based on 100.000 bootstrap simulations.

Table A3: Bias-adjusted VAR parameter estimates for the VAR model in section 3.3. Denmark 1947-1996. 


\begin{tabular}{c|ccccc} 
& \multicolumn{5}{|c}{$\operatorname{VAR}(1)$} \\
& $e_{t+1}$ & $x_{t+1}$ & $r_{t+1}$ & $\delta_{t+1}$ & $\Delta i_{t+1}$ \\
\hline$e_{t}$ & -0.143 & -0.281 & -0.052 & 0.306 & 0.016 \\
& $(0.133)$ & $(0.078)$ & $(0.037)$ & $(0.167)$ & $(0.010)$ \\
$x_{t}$ & 0.036 & -0.121 & 0.093 & -0.303 & -0.043 \\
& $(0.227)$ & $(0.127)$ & $(0.062)$ & $(0.283)$ & $(0.017)$ \\
$r_{t}$ & -0.339 & 0.055 & 0.599 & 0.189 & -0.025 \\
& $(0.413)$ & $(0.230)$ & $(0.100)$ & $(0.514)$ & $(0.029)$ \\
$\delta_{t}$ & 0.021 & -0.087 & -0.024 & 0.948 & 0.008 \\
& $(0.054)$ & $(0.030)$ & $(0.014)$ & $(0.068)$ & $(0.004)$ \\
$\Delta i_{t}$ & 1.236 & 1.061 & 1.226 & -3.499 & -0.225 \\
& $(1.764)$ & $(0.979)$ & $(0.480)$ & $(2.194)$ & $(0.120)$
\end{tabular}

\begin{tabular}{|c|c|c|c|c|c|}
\hline & \multicolumn{5}{|c|}{$\operatorname{VAR}(2)$} \\
\hline & $e_{t+1}$ & $x_{t+1}$ & $r_{t+1}$ & $\delta_{t+1}$ & $\Delta i_{t+1}$ \\
\hline \multirow[t]{2}{*}{$e_{t}$} & -0.147 & -0.242 & -0.048 & 0.543 & \\
\hline & (0.107) & $(0.073)$ & $(0.035)$ & $(0.225)$ & \\
\hline \multirow[t]{2}{*}{$x_{t}$} & & -0.177 & 0.079 & & \\
\hline & & $(0.117)$ & (0.058) & & \\
\hline \multirow[t]{2}{*}{$r_{t}$} & & & 0.609 & & \\
\hline & & & $(0.095)$ & & \\
\hline \multirow[t]{2}{*}{$\delta_{t}$} & & -0.070 & -0.026 & 1.260 & 0.011 \\
\hline & & $(0.028)$ & $(0.014)$ & $(0.179)$ & $(0.003)$ \\
\hline \multirow[t]{2}{*}{$\Delta i_{t}$} & & & 1.265 & & \\
\hline & & & $(0.442)$ & & \\
\hline \multicolumn{6}{|l|}{$e_{t-1}$} \\
\hline \multirow[t]{2}{*}{$x_{t-1}$} & -0.352 & & & & 0.049 \\
\hline & $(0.190)$ & & & & $(0.014)$ \\
\hline \multirow[t]{2}{*}{$r_{t-1}$} & & 0.347 & & & -0.052 \\
\hline & & $(0.213)$ & & & $(0.026)$ \\
\hline \multirow[t]{2}{*}{$\delta_{t-1}$} & 0.082 & & & -0.399 & \\
\hline & (0.048) & & & $(0.177)$ & \\
\hline \multirow[t]{2}{*}{$\Delta i_{t-1}$} & -5.436 & & 0.467 & 3.551 & \\
\hline & $(1.562)$ & & $(0.423)$ & $(1.992)$ & \\
\hline
\end{tabular}

Notes: The table reports bias-adjusted VAR parameter estimates with standard errors in parentheses, both based on 100.000 bootstrap simulations.

Table A4: Bias-adjusted VAR parameter estimates for the VAR model in section 3.4. Denmark 1922-1996. 


\begin{tabular}{c|ccccc} 
& \multicolumn{5}{|c}{$\operatorname{VAR}(1)$} \\
& $e_{t+1}$ & $x_{t+1}$ & $r_{t+1}$ & $\delta_{t+1}$ & $\Delta i_{t+1}$ \\
\hline$e_{t}$ & 0.003 & -0.182 & -0.045 & 0.063 & 0.014 \\
& $(0.143)$ & $(0.075)$ & $(0.050)$ & $(0.176)$ & $(0.010)$ \\
$x_{t}$ & 0.232 & 0.063 & 0.133 & -0.394 & -0.021 \\
& $(0.309)$ & $(0.151)$ & $(0.104)$ & $(0.375)$ & $(0.020)$ \\
$r_{t}$ & -0.501 & -0.020 & 0.579 & 0.703 & -0.008 \\
& $(0.388)$ & $(0.191)$ & $(0.117)$ & $(0.471)$ & $(0.025)$ \\
$\delta_{t}$ & 0.152 & -0.029 & -0.010 & 0.656 & 0.004 \\
& $(0.092)$ & $(0.046)$ & $(0.031)$ & $(0.111)$ & $(0.006)$ \\
$\Delta i_{t}$ & -2.178 & 0.175 & 1.556 & 0.517 & -0.103 \\
& $(2.439)$ & $(1.215)$ & $(0.817)$ & $(2.963)$ & $(0.150)$
\end{tabular}

\begin{tabular}{|c|c|c|c|c|c|}
\hline & \multicolumn{5}{|c|}{$\operatorname{VAR}(2)$} \\
\hline & $e_{t+1}$ & $x_{t+1}$ & $r_{t+1}$ & $\delta_{t+1}$ & $\Delta i_{t+1}$ \\
\hline \multirow[t]{2}{*}{$e_{t}$} & & -0.179 & -0.087 & 0.424 & 0.012 \\
\hline & & $(0.070)$ & $(0.063)$ & $(0.226)$ & (0.009) \\
\hline \multirow[t]{2}{*}{$x_{t}$} & & & 0.115 & -0.437 & \\
\hline & & & (0.099) & $(0.324)$ & \\
\hline \multirow[t]{2}{*}{$r_{t}$} & -0.413 & & 0.593 & & \\
\hline & $(0.361)$ & & $(0.114)$ & & \\
\hline \multirow[t]{2}{*}{$\delta_{t}$} & & -0.075 & -0.068 & 0.959 & 0.011 \\
\hline & & $(0.047)$ & $(0.050)$ & $(0.181)$ & $(0.006)$ \\
\hline \multirow[t]{2}{*}{$\Delta i_{t}$} & -2.949 & & 1.654 & & \\
\hline & $(2.084)$ & & $(0.763)$ & & \\
\hline \multirow[t]{2}{*}{$e_{t-1}$} & & -0.076 & & & 0.015 \\
\hline & & $(0.067)$ & & & (0.008) \\
\hline \multirow[t]{2}{*}{$x_{t-1}$} & -0.466 & -0.262 & & & 0.053 \\
\hline & $(0.294)$ & $(0.129)$ & & & $(0.016)$ \\
\hline \multirow[t]{2}{*}{$r_{t-1}$} & & 0.221 & & 0.889 & -0.028 \\
\hline & & $(0.172)$ & & $(0.451)$ & $(0.021)$ \\
\hline \multirow[t]{2}{*}{$\delta_{t-1}$} & 0.135 & & 0.066 & -0.387 & \\
\hline & $(0.082)$ & & $(0.046)$ & $(0.161)$ & \\
\hline \multirow[t]{2}{*}{$\Delta i_{t-1}$} & -4.705 & & 0.704 & 5.315 & \\
\hline & $(2.272)$ & & $(0.670)$ & $(2.591)$ & \\
\hline
\end{tabular}

Notes: The table reports bias-adjusted VAR parameter estimates with standard errors in parentheses, both based on 100.000 bootstrap simulations.

Table A5: Bias-adjusted VAR parameter estimates for the VAR model in section 3.4. Denmark 1922-1982. 


\begin{tabular}{c|ccccc} 
& \multicolumn{5}{|c}{$\operatorname{VAR}(1)$} \\
& $e_{t+1}$ & $x_{t+1}$ & $r_{t+1}$ & $\delta_{t+1}$ & $\Delta i_{t+1}$ \\
\hline$e_{t}$ & -0.207 & -0.345 & -0.025 & 0.217 & 0.014 \\
& $(0.170)$ & $(0.097)$ & $(0.022)$ & $(0.189)$ & $(0.014)$ \\
$x_{t}$ & 0.131 & -0.082 & 0.073 & -0.269 & -0.038 \\
& $(0.289)$ & $(0.155)$ & $(0.037)$ & $(0.321)$ & $(0.023)$ \\
$r_{t}$ & -0.287 & 0.551 & 0.670 & -1.346 & -0.066 \\
& $(1.068)$ & $(0.573)$ & $(0.128)$ & $(1.193)$ & $(0.080)$ \\
$\delta_{t}$ & 0.055 & -0.069 & -0.021 & 0.904 & 0.008 \\
& $(0.083)$ & $(0.045)$ & $(0.010)$ & $(0.092)$ & $(0.006)$ \\
$\Delta i_{t}$ & 1.320 & 1.623 & 1.156 & -4.969 & -0.259 \\
& $(2.121)$ & $(1.121)$ & $(0.262)$ & $(2.340)$ & $(0.151)$
\end{tabular}

\begin{tabular}{|c|c|c|c|c|c|}
\hline & \multicolumn{5}{|c|}{$\operatorname{VAR}(2)$} \\
\hline & $e_{t+1}$ & $x_{t+1}$ & $r_{t+1}$ & $\delta_{t+1}$ & $\Delta i_{t+1}$ \\
\hline$e_{t}$ & & $\begin{array}{l}-0.328 \\
(0.074)\end{array}$ & & & \\
\hline$x_{t}$ & & & $\begin{array}{c}0.091 \\
(0.031)\end{array}$ & & \\
\hline$r_{t}$ & & & $\begin{array}{c}0.455 \\
(0.151)\end{array}$ & & \\
\hline$\delta_{t}$ & $\begin{array}{c}0.198 \\
(0.067)\end{array}$ & & & $\begin{array}{c}0.830 \\
(0.080)\end{array}$ & \\
\hline$\Delta i_{t}$ & & & $\begin{array}{c}1.238 \\
(0.239)\end{array}$ & $\begin{array}{l}-3.984 \\
(1.938)\end{array}$ & $\begin{array}{l}-0.167 \\
(0.122)\end{array}$ \\
\hline$e_{t-1}$ & & & & & \\
\hline$x_{t-1}$ & $\begin{array}{l}-0.417 \\
(0.214)\end{array}$ & & $\begin{array}{c}0.054 \\
(0.033)\end{array}$ & $\begin{array}{c}0.305 \\
(0.251)\end{array}$ & $\begin{array}{c}0.051 \\
(0.017)\end{array}$ \\
\hline$r_{t-1}$ & $\begin{array}{c}1.895 \\
(0.828)\end{array}$ & $\begin{array}{c}0.956 \\
(0.359)\end{array}$ & $\begin{array}{c}0.430 \\
(0.146)\end{array}$ & $\begin{array}{l}-3.005 \\
(0.917)\end{array}$ & $\begin{array}{c}-0.286 \\
(0.056)\end{array}$ \\
\hline$\delta_{t-1}$ & & & & & \\
\hline$\Delta i_{t-1}$ & $\begin{array}{l}-3.656 \\
(1.793)\end{array}$ & & $\begin{array}{c}0.692 \\
(0.295)\end{array}$ & & $\begin{array}{c}-0.315 \\
(0.131)\end{array}$ \\
\hline
\end{tabular}

Notes: The table reports bias-adjusted VAR parameter estimates with standard errors in parentheses, both based on 100.000 bootstrap simulations.

Table A6: Bias-adjusted VAR parameter estimates for the VAR model in section 3.4. Denmark 1947-1996. 